University of Nebraska - Lincoln

DigitalCommons@University of Nebraska - Lincoln

1996

\title{
Detailed observations of California foreshock sequences: Implications for the earthquake initiation process
}

\author{
Douglas A. Dodge \\ Stanford University \\ Gregory C. Beroza \\ Stanford University \\ W. L. Ellsworth \\ U.S. Geological Survey
}

Follow this and additional works at: https://digitalcommons.unl.edu/usgsstaffpub

Part of the Earth Sciences Commons

Dodge, Douglas A.; Beroza, Gregory C.; and Ellsworth, W. L., "Detailed observations of California foreshock sequences: Implications for the earthquake initiation process" (1996). USGS Staff -- Published Research. 390.

https://digitalcommons.unl.edu/usgsstaffpub/390

This Article is brought to you for free and open access by the US Geological Survey at DigitalCommons@University of Nebraska - Lincoln. It has been accepted for inclusion in USGS Staff -- Published Research by an authorized administrator of DigitalCommons@University of Nebraska - Lincoln. 


\title{
Detailed observations of California foreshock sequences: Implications for the earthquake initiation process
}

\author{
Douglas A. Dodge and Gregory C. Beroza \\ Department of Geophysics, Stanford University, Stanford, California \\ W. L. Ellsworth \\ U.S. Geological Survey, Menlo Park, Califomia
}

\begin{abstract}
We find that foreshocks provide clear evidence for an extended nucleation process before some earthquakes. In this study, we examine in detail the evolution of six California foreshock sequences, the 1986 Mount Lewis $\left(M_{L}=5.5\right)$, the 1986 Chalfant $\left(M_{L}=6.4\right)$, the 1986 Stone Canyon $\left(M_{L}=4.7\right)$, the 1990 Upland $\left(M_{L}=5.2\right)$, the 1992 Joshua Tree $\left(M_{W}=6.1\right)$, and the 1992 Landers $\left(M_{W}=7.3\right)$ sequence. Typically, uncertainties in hypocentral parameters are too large to establish the geometry of foreshock sequences and hence to understand their evolution. However, the similarity of location and focal mechanisms for the events in these sequences leads to similar foreshock waveforms that we cross correlate to obtain extremely accurate relative locations. We use these results to identify small-scale fault zone structures that could influence nucleation and to determine the stress evolution leading up to the mainshock. In general, these foreshock sequences are not compatible with a cascading failure nucleation model in which the foreshocks all occur on a single fault plane and trigger the mainshock by static stress transfer. Instead, the foreshocks seem to concentrate near structural discontinuities in the fault and may themselves be a product of an aseismic nucleation process. Fault zone heterogeneity may also be important in controlling the number of foreshocks, i.e., the stronger the heterogeneity, the greater the number of foreshocks. The size of the nucleation region, as measured by the extent of the foreshock sequence, appears to scale with mainshock moment in the same manner as determined independently by measurements of the seismic nucleation phase. We also find evidence for slip localization as predicted by some models of earthquake nucleation.
\end{abstract}

\section{Introduction}

A key question in earthquake source mechanics is how do earthquakes begin. Do big earthquakes begin in the same manner as small earthquakes, or is there something different about the initiation process of large versus small events? If there is a difference, then large earthquakes may be predictable. Otherwise, earthquake prediction might require more detailed knowledge of the stress and strength distributions on faults than we are ever likely to have. Experimental and theoretical work [e.g., Das and Scholz, 1981; Dieterich, 1986, 1992; Ohnaka, 1992; Yamashita and Ohnaka, 1991] indicates that earthquakes should be preceded by quasi-static slip within a nucleation zone. If real earthquakes begin this way and if the slip extent of the nucleation zone is sufficiently large, then it might be possible to detect the nucleation process. Observations to date have failed to detect direct evidence of the nucleation process such as a strain signal generated by aseismic slip prior to earthquakes [Johnston et al., 1990, 1994; Abercrombie et al., 1995].

Foreshocks are the most obvious manifestation of earthquake nucleation and, as such, can provide important constraints on the mechanics of the process. While a great deal is known about the

Copyright 1996 by the American Geophysical Union.

Paper number 96JB02269.

0148-0227/96/96JB-02269\$09.00 statistics of foreshocks [Jones and Molnar, 1979; Jones, 1984; Abercrombie and Mori, 1995], foreshock mechanics have not generally been closely analyzed. One reason for this is that uncertainties in foreshock locations are often large relative to the dimensions of the sequence. Most earthquakes occur in sparsely instrumented areas where the detection and precise location of foreshocks may be problematic; however, even in well-instrumented areas, typical location uncertainties are on the order of the dimensions of a foreshock sequence, and one cannot easily draw conclusions about the interactions among the foreshocks.

Recently, Dodge et al. [1995] relocated the foreshocks of the 1992 Landers $M_{W}=7.3$ earthquake using waveform cross correlation to determine accurate $P$ wave and $S$ wave relative arrival times. The resulting locations had relative uncertainties of less than $100 \mathrm{~m}$ horizontally and $200 \mathrm{~m}$ vertically. With this level of resolution one can begin to test competing models for earthquake nucleation and foreshock generation. Specifically, one can distinguish between models in which foreshocks are a byproduct of an aseismic nucleation process and models in which the foreshock stress changes contribute to a cascading failure culminating in the mainshock. This distinction is made on the basis of the stress changes caused by the foreshocks. If the foreshocks are part of such a cascading failure process, then they should push the mainshock toward failure, i.e. act to increase the shear traction, reduce the normal stress, or increase the pore pressure on the mainshock fault plane. Alternatively, if the foreshocks are triggered by an aseismic process or if something other than stress 
changes causes triggering, there need be no causative relation between the foreshock stress changes and the mainshock occurrence.

Dodge et al. [1995] estimated the stress change at the Landers mainshock hypocenter, due to the foreshocks and found that the foreshocks acted to de-stress the mainshock. However, our original point estimate of the stress change did not include the uncertainties in the hypocentral parameters. In this study, we extend our analysis to produce Stress-change distribution functions, consider the possible role that pore fluid effects can play in the failure process, and analyze five other California foreshock sequences to see whether the Landers results generalize to other earthquakes.

\section{Relocation Procedure}

The first step in studying the mechanics of foreshocks is to obtain accurate locations. This process requires improving the velocity model, minimizing errors in arrival picks, and obtaining a sufficient number and azimuthal distribution of observations to make the hypocentral estimation problem well constrained. Since only relative locations are required in our case, the problems with the velocity model can be minimized by using the arrival times to simultaneously estimate hypocenters, velocity model corrections, and station corrections. The foreshocks occupy small volumes so the ray paths are similar, and almost all the unmodeled velocity structure can be absorbed in the station corrections. We use the VELEST earthquake location program [Ellsworth, 1977; Roecker, 1981] to estimate velocity model and station corrections.

We use waveform cross correlation to minimize pick errors and to obtain additional $\boldsymbol{P}$ and $\boldsymbol{S}$ wave arrival picks. Both time domain and frequency domain cross correlation techniques have been used to produce high-precision relative earthquake locations by Poupinet et al. [1984], Fremont and Malone [1987], Deichmann and Garcia-Fernandez [1992], and Dodge et al. [1993]. Although the foreshock sequences we analyze are compact, there is typically enough waveform diversity within a sequence that no single event can be found that correlates well with all (or even most of) the other foreshocks. Our first solution to this problem [Dodge et al., 1995] was to use a technique developed by VanDecar and Crosson [1990] for determining relative arrival times of teleseisms recorded by a regional seismic network. This technique uses the cross correlations between all pairs of signals with a weighted least squares adjustment of the corresponding shifts to determine an optimum set of arrival time corrections and estimates of the errors in the resulting adjusted picks.

Although we had considerable success with the least squares approach, it has limitations. Often, the seismograms from a given sequence form distinct groups, highly similar within each group, but very different from group to group. If we attempt to adjust all seismograms simultaneously, we encounter problems with cycle skipping. Also, the seismograms of the larger earthquakes in each sequence are often strongly clipped, and their arrivals must be picked by hand. The results must be carefully inspected for consistency, or the larger event locations may be systematically skewed relative to the smaller events. Our current repicking algorithm first identifies groups of similar seismograms within a sequence and then allows interactive picking of the first arrival for the single seismogram with the highest signal-to-noise ratio in each group. These picks are then fixed, and the remaining group members adjusted by least squares.

One of the major advantages claimed for cross-correlationderived picks has been that one can achieve subsample precision [Poupinet et al., 1984; Fremont and Malone, 1987]. For instance, if the seismograms are digitized at 100 samples per second, the cross-correlation times may have a relative precision of the order of 1-2 ms. In the absence of other sources of error this precision implies relative source location errors of a few tens of meters at most. By introducing hand picks, it might appear that we throw away all the gains in accuracy obtained with cross correlation; however, in our experience, cross correlation reduces errors on two levels. The first and most dramatic improvement in accuracy is from the reduction or elimination of pick errors in excess of one sample. By analogy with the example just cited, this level of timing precision can limit source location errors to about $100 \mathrm{~m}$. At this level, cross correlation is essentially a tool to correct pick errors. Impulsive arrivals with high signal-to-noise ratios are generally picked quite precisely by network analysts. However, as the signal-to-noise ratio decreases, the arrivals become increasingly indistinct until, at some point, the trace is not used. Within that region of decreasing usability, pick errors in excess of one sample are common, and our technique removes this error. Within groups we are able to achieve subsample timing precision. However, since groups of seismograms are tied together by hand picks, the relative positions of the groups are not as well determined as the relative position of seismograms within a group.

Figure 1 illustrates the results of this process. These are two groups of seismograms ranging in magnitude from 0.9 to 2.0. For each group, the trace marked with an upward pointing arrow has a clear arrival and the other picks are chosen relative to that arrival. In ensemble, all the picks make sense. However, if these traces were picked in isolation, it is likely that the picks would scatter by at least several hundredths of a second relative to the picks shown. Some of the traces might not have been picked at all by the network analysts, in which case we gain additional observations through cross-correlation picking. Figure 1 is also intended to show how picking the $P$ wave arrivals in ensemble can help improve the quality of the focal mechanism determinations. By observing all the traces of a group simultaneously, one can easily identify and repair missing or discrepant polarity assignments. Figure 2 shows an example of the hypocenter location improvement resulting from our repicking process. Each panel shows the seismicity relocated by joint hypocenter determination (JHD) using network picks from the Northem California Earthquake Center (NCEC) database (top), and the same seismicity relocated by JHD using cross-correlation picks (bottom). Figure 2 (left) panel shows map views of the preshocks, and Figure 2 (right) shows cross sectional views.

Both sets of locations indicate a rather narrow, N-S trending set of epicenters, but only the second set of locations suggests the change in strike about $1 \mathrm{~km}$ from the southern end and the subsidiary branch of seismicity to the northwest. Note that even though there are over $\mathbf{8 0 0}$ additional observations in the second set of locations, the average residual is about half that of the first set of locations. This is a clear indication of the greater consistency of the observations in the second set of locations. The foreshock sequences analyzed in this study have all been relocated using high-precision picks, and in every case the resulting locations have significantly lower average residuals and smaller standard errors than locations made using uncorrected picks. 


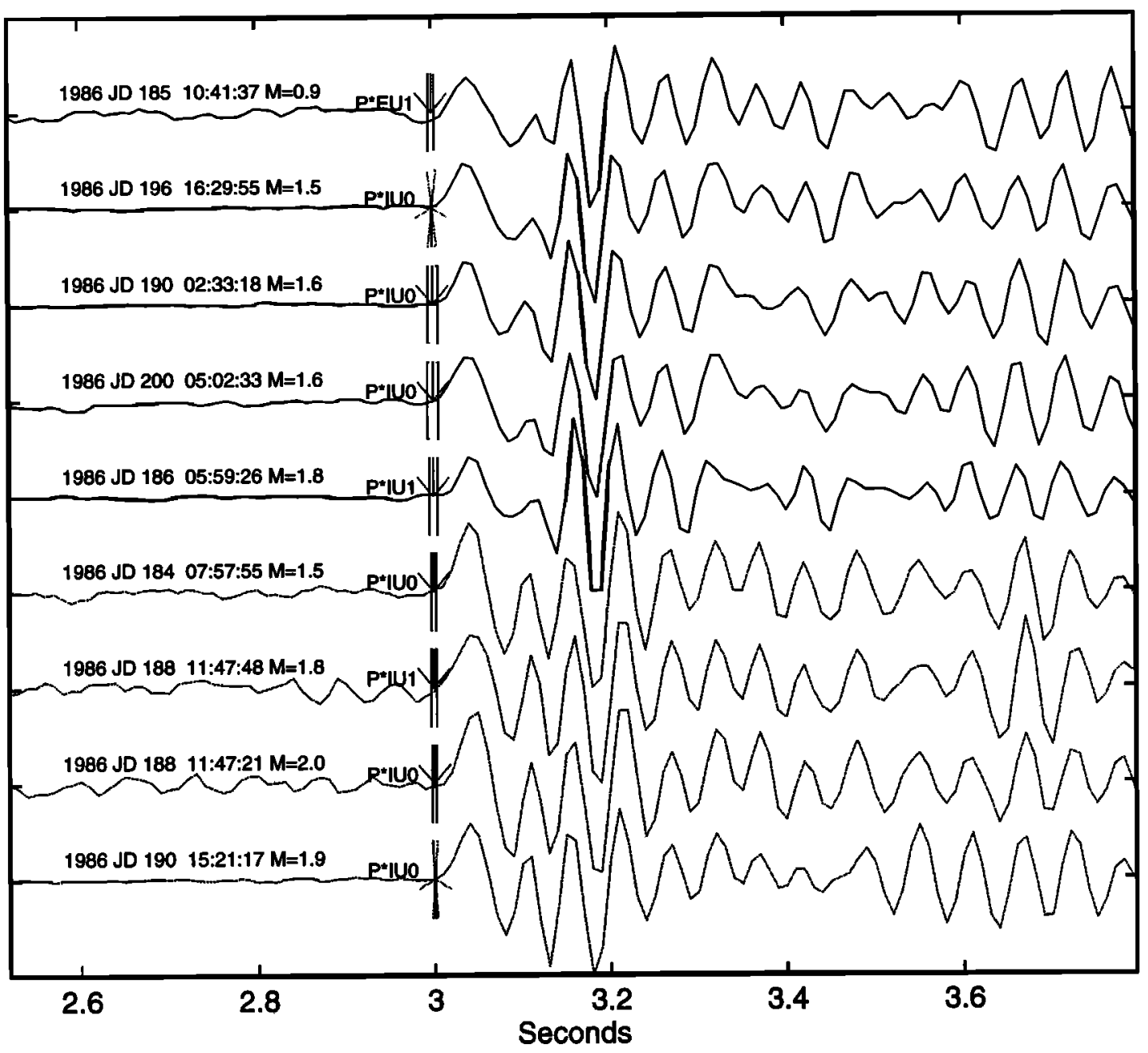

Figure 1. Waveforms from some Chalfant foreshocks recorded at station WVD aligned by cross correlation with resulting $P$ wave picks. Bottom trace has highest signal-to-noise ratio, and its onset is unambiguous. Remaining onsets have varying amounts of ambiguity that would likely cause picks made in isolation to scatter by several samples relative to the cross-correlation picks.

\section{Foreshock Sequences}

Our data in this study are seismograms recorded by the northern California, southern California, and University of Nevada, Reno, short-period seismic networks. These are verticalcomponent velocity seismograms recorded on $1-\mathrm{Hz}$ sensors. Tens of thousands of such digital recordings are available, and given that approximately $44 \%$ of California and Nevada earthquakes with $M_{L}>5$ have at least one immediate foreshock [Jones, 1984; Abercrombie and Mori, 1995], one might expect a large number of foreshock sequences would have been recorded. However, the Northern California Earthquake Data Center and Southern Califomia Earthquake Center databases contain 108 earthquakes with $M_{L}>5$ between 1981 and 1996. Of these, 55 were preceded by at least one earthquake within $2 \mathrm{~km}$ and within 30 days. Thirty-six of those earthquakes occurred within the aftershock sequence of a larger earthquake or were part of a swarm with no distinct mainshock. Of the remaining events, 11 had only one foreshock and 2 had poorly recorded foreshocks. This left six earthquakes with usable foreshock sequences. These are the 1986 Stone Canyon earthquake $\left(M_{L}=4.7\right)$, the 1986 Mount Lewis earthquake $\left(M_{L}=5.7\right)$, the 1986 Chalfant principal foreshock ( $M$ $=5.8)$, the 1990 Upland earthquake $\left(M_{L}=5.2\right)$, the 1992 Joshua
Tree earthquake $(M W=6.1)$, and the 1992 Landers earthquake $(M W=7.3)$. The mainshock locations for these sequences are shown in Figure 3, and summary statistics for each sequence are in Table 1.

\section{Mount Lewis Sequence}

The 1986 Mount Lewis earthquake $\left(M_{L}=5.7\right.$ ) occurred on a near-north striking fault about $18 \mathrm{~km}$ north of the 1984 Morgan Hill earthquake $\left(M_{L}=6.2\right)$ epicenter. Although the epicentral region had been nearly devoid of seismicity since 1943 [Zhou et al., 1993], earthquakes began occurring within $2 \mathrm{~km}$ of the eventual Mount Lewis epicenter 8 days after the Morgan Hill mainshock. In all, there were 110 earthquakes located by the U.S. Geological Surver (USGS) Calnet network within $2 \mathrm{~km}$ of the Mount Lewis epicenter between May 1, 1984, and March 31, 1986, the date of the Mount Lewis mainshock. Zhou et al. [1993] observed that most of the preshocks to the Mount Lewis earthquake were in one of two swarms. The first swarm of about 19 events started on September 24, 1985, and remained active for about 2 weeks. The second swarm was the immediate foreshock sequence of 18 events. It started on March 6, 1986, 25 days before the mainshock, but was most active on March 24. Zhou et 
JHD using network picks
$1383 \mathrm{P}$ wave picks $44 \mathrm{~S}$ wave picks RMS $=.026 \quad 2 \sigma_{\mathrm{h}}=190 \mathrm{~m} \quad 2 \sigma_{\mathrm{v}}=272 \mathrm{~m}$

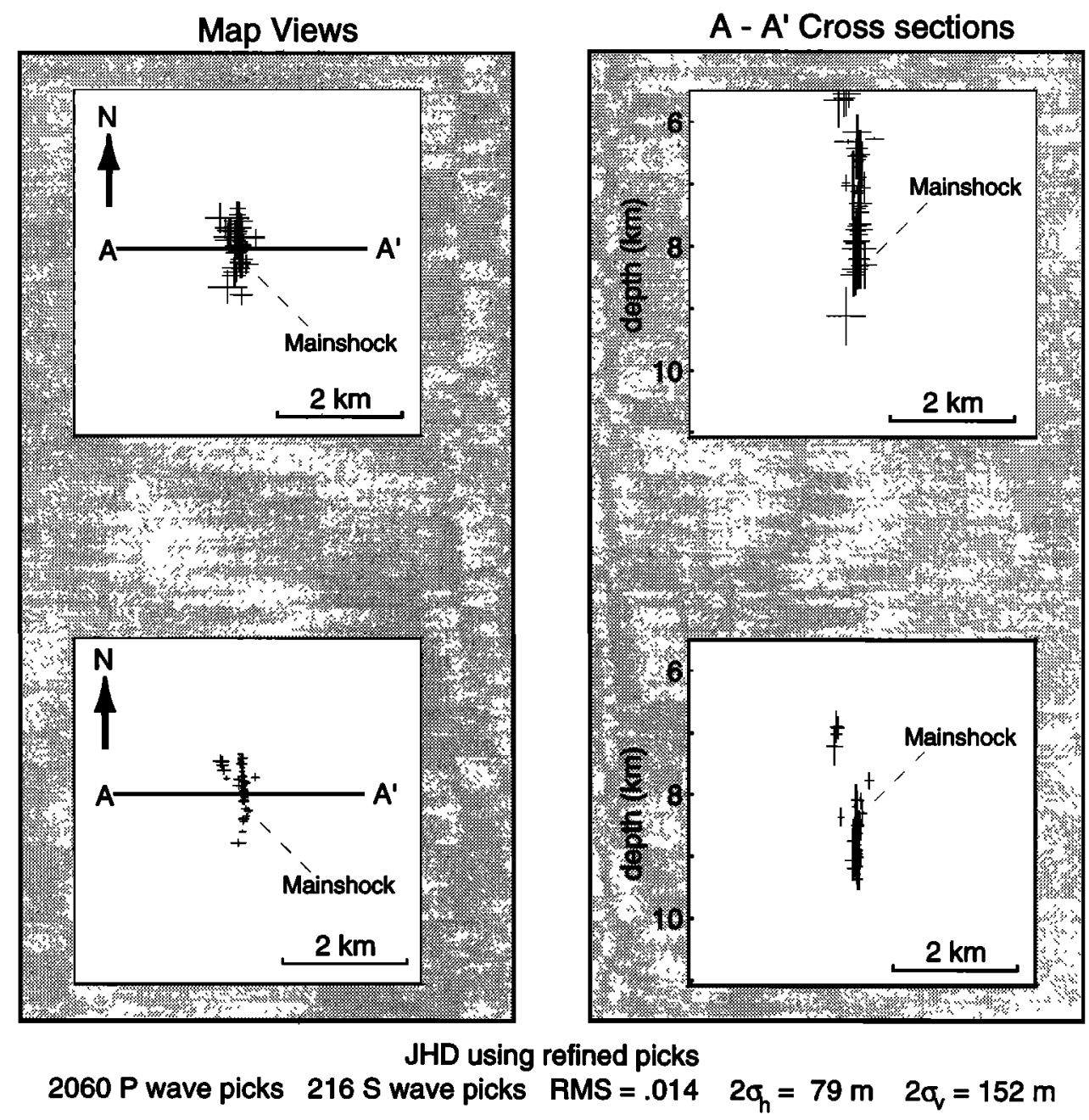

Figure 2. Comparison of relocations using network picks and cross-correlation-derived picks with (left) a map view and (right) a cross section looking to the north. (top) Fifty preshocks to the Mount Lewis earthquake relocated by joint hypocenter determination (JHD) using network picks. (bottom) The same events relocated by JHD but using the cross-correlation-derived picks. Note that although there are 677 more observations in the second set of relocations, the average residual decreased from 0.026 to $0.014 \mathrm{~s}$. The average $2 \sigma$ uncertainties have decreased from 190 to $79 \mathrm{~m}$ (horizontal) and from 272 to $152 \mathrm{~m}$ (vertical).

al. [1993] also noted that the preshocks could be divided into two groups based on focal mechanisms. Their group A preshocks produced a composite focal mechanism with a strike of $355^{\circ}$ and their group B preshock composite focal mechanism had a strike of $5^{\circ}$.

Figure 4 shows the locations in map and cross-sectional views of 49 preshocks and the mainshock. These are all the events with usable waveforms available. The events of the first swarm are shown as large open circles. The immediate foreshocks (swarm 2) are shown as asterisks. The swarm 1 events form a distinct group about $0.7 \mathrm{~km}$ in N-S extent and a little over $1 \mathrm{~km}$ in vertical extent. All the swarm 1 events are north of the mainshock, and most of them are deeper. Strike statistics for the two groups were determined by generating 200 realizations of the epicentral coordinates for all the events and, for each realization, fitting a line through the epicenters by least squares. This provided 200 estimates of strike for each group. On the basis of these estimates, the swarm 1 events occurred on a fault plane striking about $351^{\circ} \pm 2.6^{\circ}$. The immediate foreshocks form a distinctly different group. They are centered below the mainshock hypocenter, and most of them are deeper than the swarm 1 events. There is little overlap between the two groups, but they may abut. The immediate foreshocks extend about $1.1 \mathrm{~km}$ along strike and range in depth from about 8.5 to $9.2 \mathrm{~km}$. From the point of contact with the swarm 1 events to the south, the immediate foreshock epicenters lie on a line striking $1^{\circ} \pm 2.1^{\circ}$. From the point of contact north they take on the strike of the swarm 1 preshocks. Evidently, these two swarms are adjacent to a change in strike on the fault. The mainshock hypocenter is less than $250 \mathrm{~m}$ from the point where the fault appears to change strike, and the mainshock focal mechanism has a strike of $355^{\circ}$.

This interpretation is supported by the focal mechanisms. Figure 5 shows focal mechanisms for the swarm 1 and swarm 2 (immediate foreshocks) events computed using the FPFIT program [Reasenberg and Oppenheimer, 1985]. These are all the focal mechanisms determined using 15 or more first motions for all the relocated swarm 1 and swarm 2 events, but excluding six events in the region where the two swarms overlap and the focal 


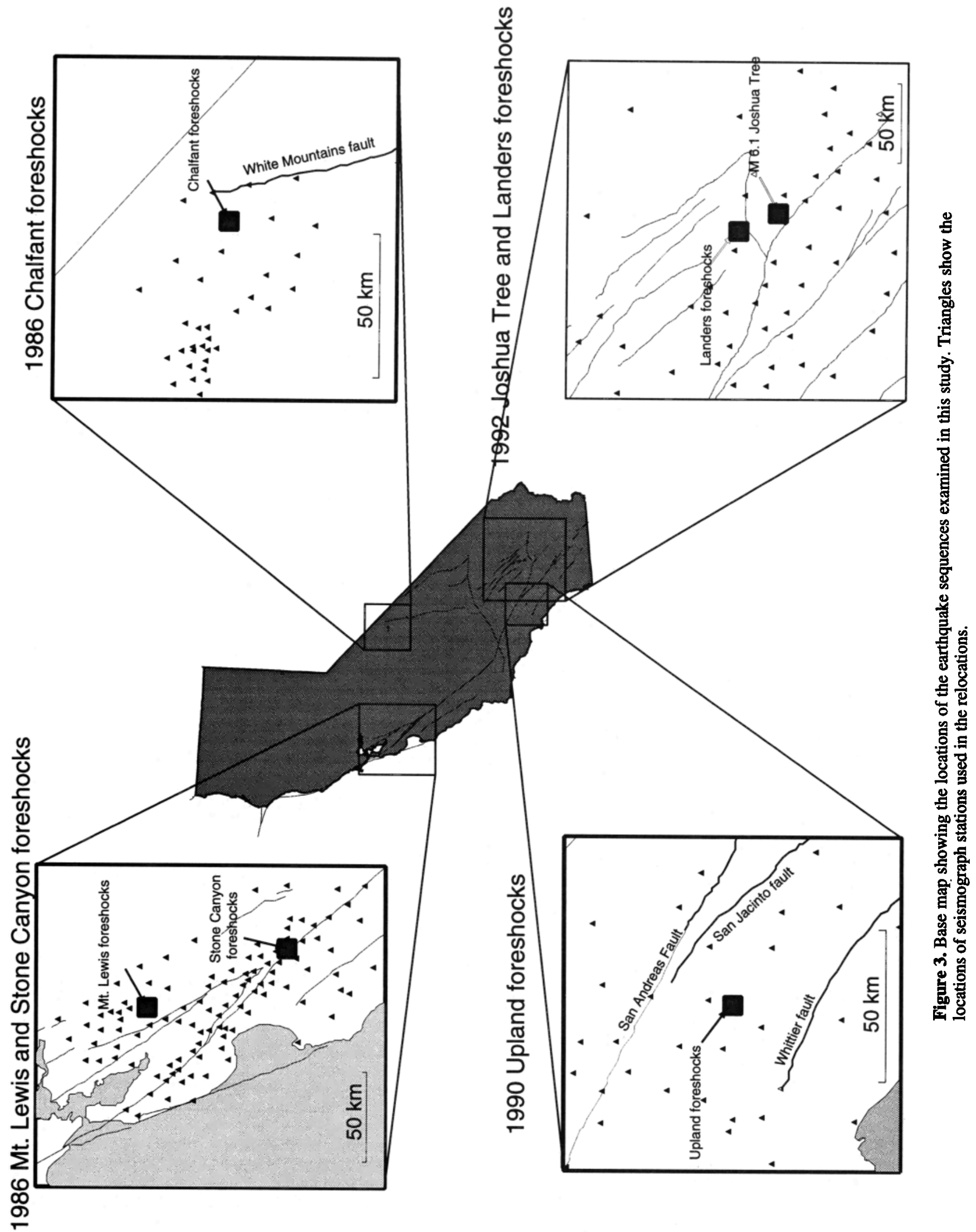


Table 1. Foreshock Sequences Analyzed

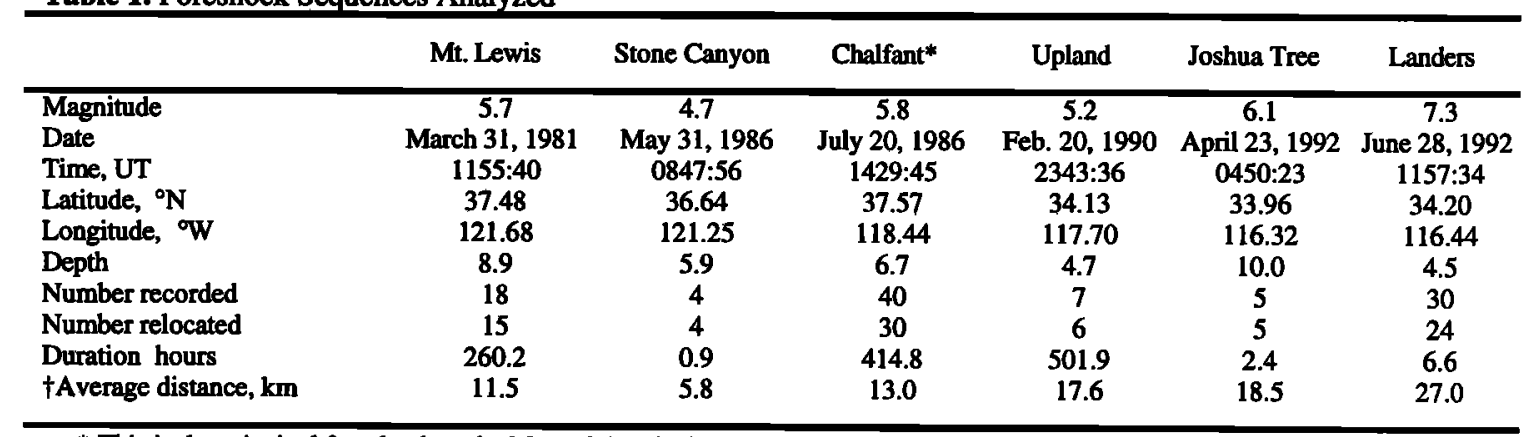

* This is the principal foreshock to the $M_{L}=6.4$ mainshock.

$\dagger$ Values show the average distance from the mainshock of the five nearest stations for each sequence.

mechanisms vary in strike between the two groups. The average strike of the swarm 1 events is $350^{\circ}$, with a standard error of $8^{\circ}$. The average strike of the immediate foreshocks and mainshock is $0^{\circ}$, with a standard error of $6^{\circ}$ The agreement between the strike from the seismicity and the strike from the focal mechanism

\section{Map View}

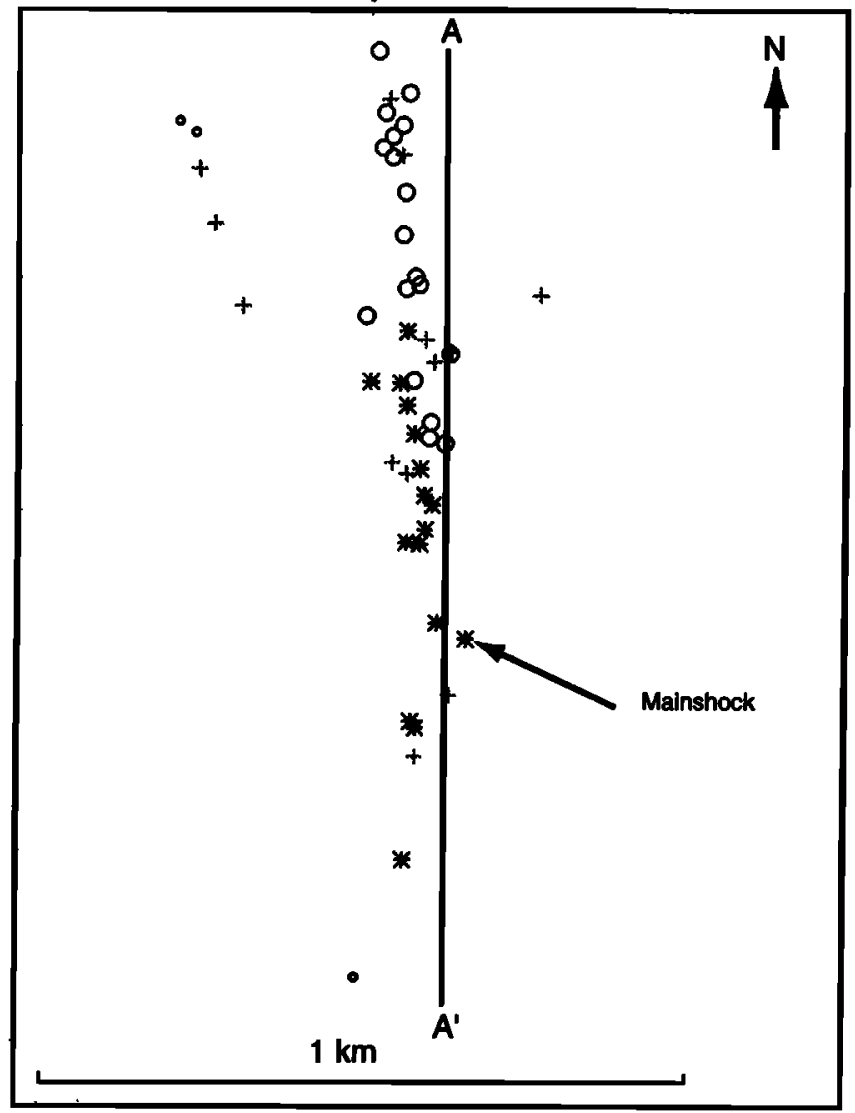

determinations is good (for the swarm 1 events $351^{\circ}$, versus $350^{\circ}$, and for the swarm 2 events, $1^{\circ}$ versus $0^{\circ}$ ).

Figure 6 shows a close-up view of the mainshock and 15 immediate foreshocks that we were able to relocate. In this figure the events are shown as disks oriented according to the preferred
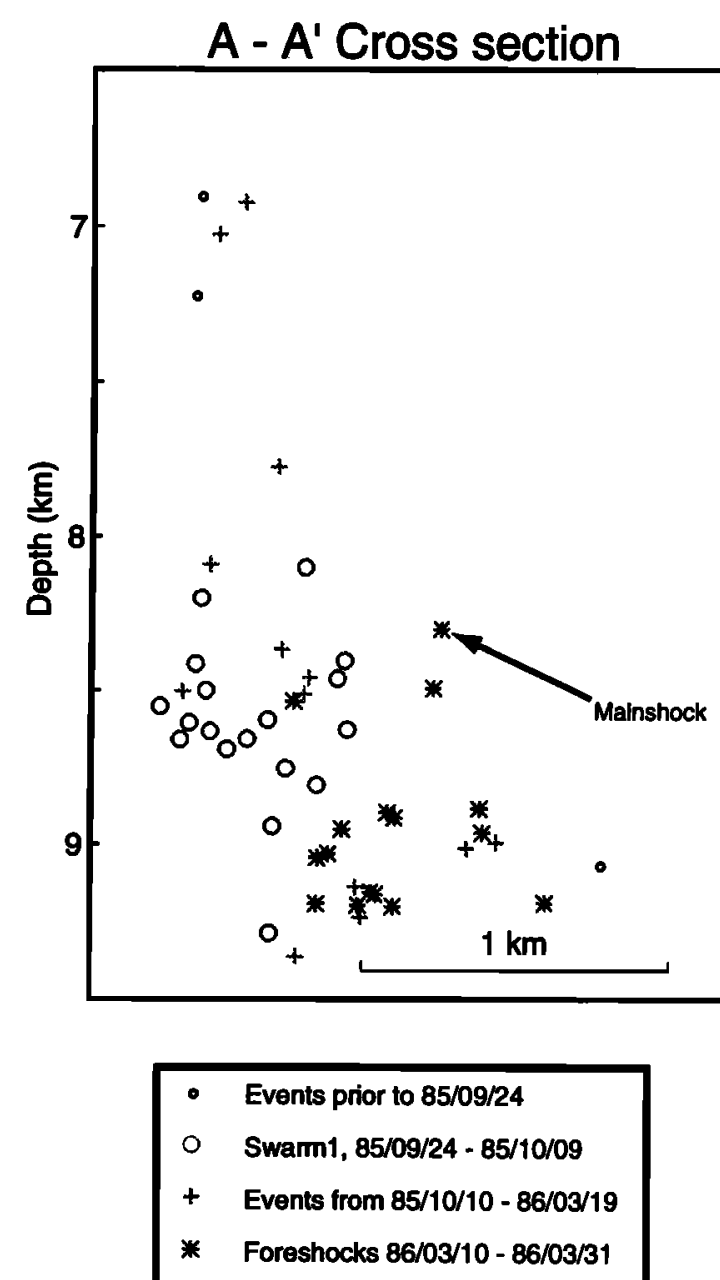

Figure 4. Relocated seismicity in the Mount Lewis epicentral region from July 1984 to March 31, 1986, (left) map view and (right) cross section. Events shown as circles are from the swarm that occurred in late 1985. These earthquakes are all north of the mainshock hypocenter and centered at a depth of about $8.5 \mathrm{~km}$. The strike of the seismicity is about $352^{\circ}$. The immediate foreshocks are shown as asterisks and are mostly south of the events of the first swarm. Their average depth is about $0.5 \mathrm{~km}$ deeper than the earlier events. Except in the region of overlap with the earlier events, the strike of their epicenters is about $3^{\circ}$. The mainshock epicenter is located within $250 \mathrm{~m}$ of the change in strike of the two sequences. The four events at about $7 \mathrm{~km}$ depth west of the first swarm apparently
occurred on a nearby fault striking more to the west. 


\section{Mt. Lewis Foreshocks}

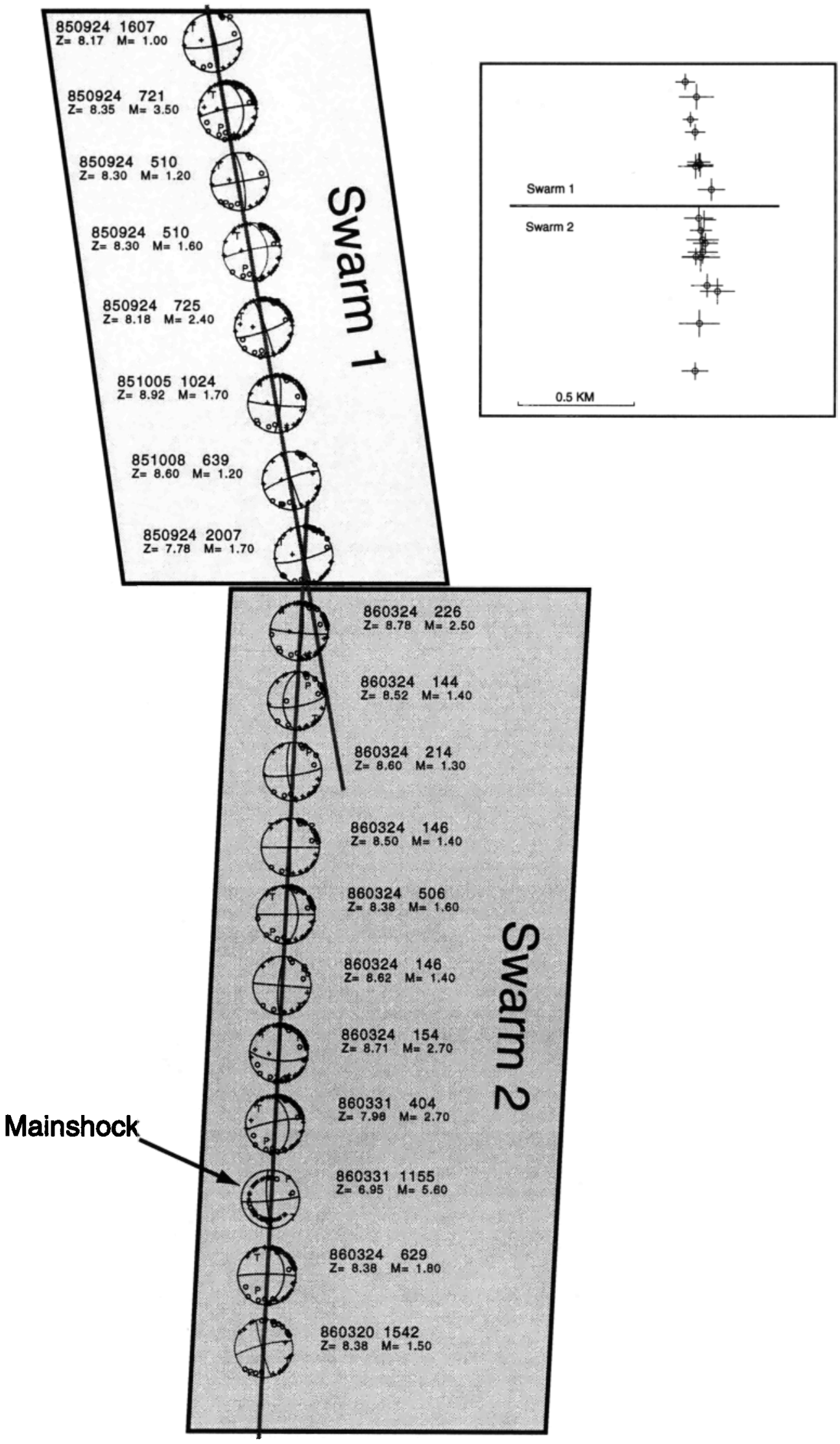

Figure 5. Well-constrained focal mechanisms with first motion polarities for the swarm 1 and swarm 2 events of the Mount Lewis sequence. Lower hemisphere plots are shown superimposed on lines with the strike of the seismicity for each group. Events are shown in order of spatial occurrence. Inset shows the actual location of the swarm events with location uncertainties. 

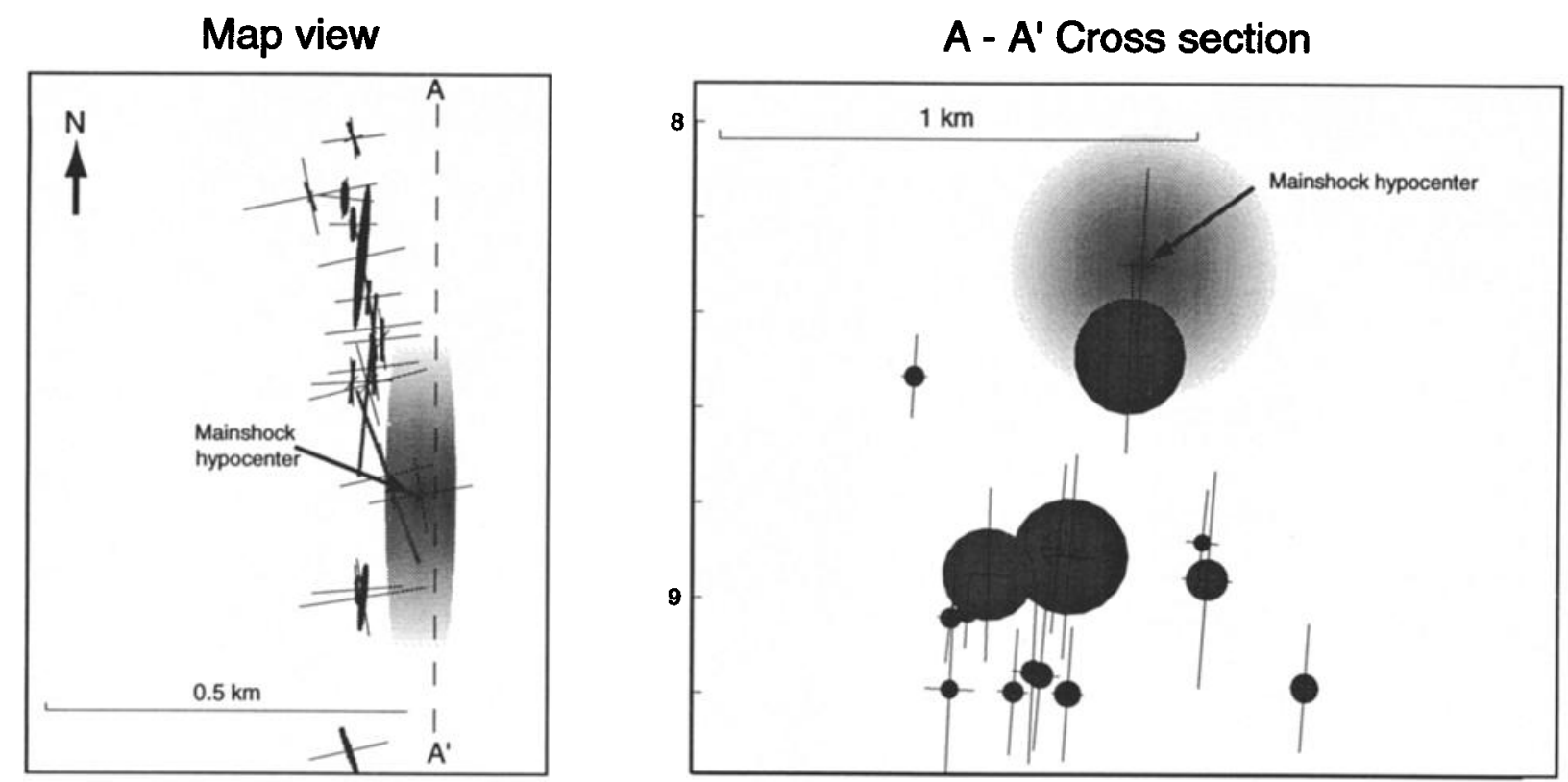

$$
\text { f } 95 \% \text { confidence limits }
$$

Figure 6. Relocated immediate foreshock and mainshock hypocenters for the Mount Lewis sequence, (left) map view and (right) cross section. Events are shown as disks with orientation determined from the focal mechanism solution. The size of the disks is estimated assuming a 3.0-MPa stress drop. (Mainshock disk is truncated so that details of sequence are preserved.) Crosses show the axes of the $95 \%$ confidence ellipsoids for the relative locations. The same method of presentation is used in later figures showing relocated foreshock sequences.

nodal plane of the focal mechanisms and view direction. The size of the disks is based on a 3-MPa stress drop in this and all subsequent plots of this type. However, in the stress change calculations presented later, stress drops were allowed to vary between 0.1 and $100 \mathrm{MPa}$. The crosses are the axes of the $95 \%$ confidence ellipsoids for the relative locations. The mainshock hypocenter is just south of the transition from near N-S fault strike to a more northwesterly strike shown in Figure 5. The $M_{L}$ $=2.7$ foreshock that occurred 8 hours prior to the mainshock is the event closest to the mainshock hypocenter. Because of its size and proximity, it has a major effect on the stress change calculations discussed later in this paper.

\section{Stone Canyon Sequence}

The May 31,1986 , Stone Canyon earthquake $\left(M_{L}=4.7\right)$ was the last of a series of six $M_{L}=4$ earthquakes that occurred on the creeping section of the San Andreas fault near Hollister between August 1982 and June 1986 [Wyss and Habermann, 1988]. The ruptures of the six earthquakes, defined by aftershock zones, abut each other to form an approximately $20-\mathrm{km}$ long by $5-\mathrm{km}$ deep patch that slipped during this period of activity. The May 1986 Stone Canyon earthquake occurred in a seismic gap between the first and third events of the series and was preceded by four immediate foreshocks within an hour of the mainshock.

Figure 7 shows a map view of relocated seismicity for the time period July 1984 to the time of the mainshock in May 1986 within a region $4 \mathrm{~km}$ long by $4 \mathrm{~km}$ deep and centered on the mainshock. At the resolution of these relocations there is little evidence for structural irregularity influencing the location of the mainshock hypocenter. Although the epicenters of the mainshock and immediate foreshocks appear to be displaced somewhat to the NE from the other epicenters, the offset is of the order of the uncertainties in the locations and may be an artifact. The location of the mainshock may be influenced by stress heterogeneity resulting from the earthquake of August 10, 1982. The region to the NW of the 1986 mainshock was not ruptured during the previous earthquakes, but the region to the SE ruptured during the 1982 earthquake. From the mainshock epicenter to the SE there are only seven earthquakes, but to the NW there are 25 earthquakes during this time period. This relative lack of earthquakes to the $\mathrm{SE}$ is consistent with that region having been destressed from the 1982 earthquake, with the sudden transition to a higher seismicity rate at the mainshock location possibly marking the transition to the higher-stress, unruptured region, which ruptured in the May 1986 mainshock.

Figure 8 shows a more detailed view of the immediate foreshocks and mainshock. The earthquakes are shown as oriented disks, and the crosses are the axes of the $95 \%$ confidence ellipsoids for the relative locations. The foreshocks are clustered within a region about $200 \mathrm{~m}$ in length by $350 \mathrm{~m}$ in depth. The width of the foreshock zone is a little over $100 \mathrm{~m}$. However, since the uncertainties in the locations are a substantial fraction of the width, it is difficult to tell how much of the width is real and how much is due to errors in the foreshock relocation.

\section{Chalfant Sequence}

The 1986 Chalfant, California, earthquake $\left(M_{L}=6.4\right)$ occurred on July 21, 1986, in the Bishop-Mammoth Lakes area. The mainshock was preceded by a $M_{L}=5.7$ foreshock that occurred about 24 hours earlier and $3 \mathrm{~km}$ to the north on an apparent 


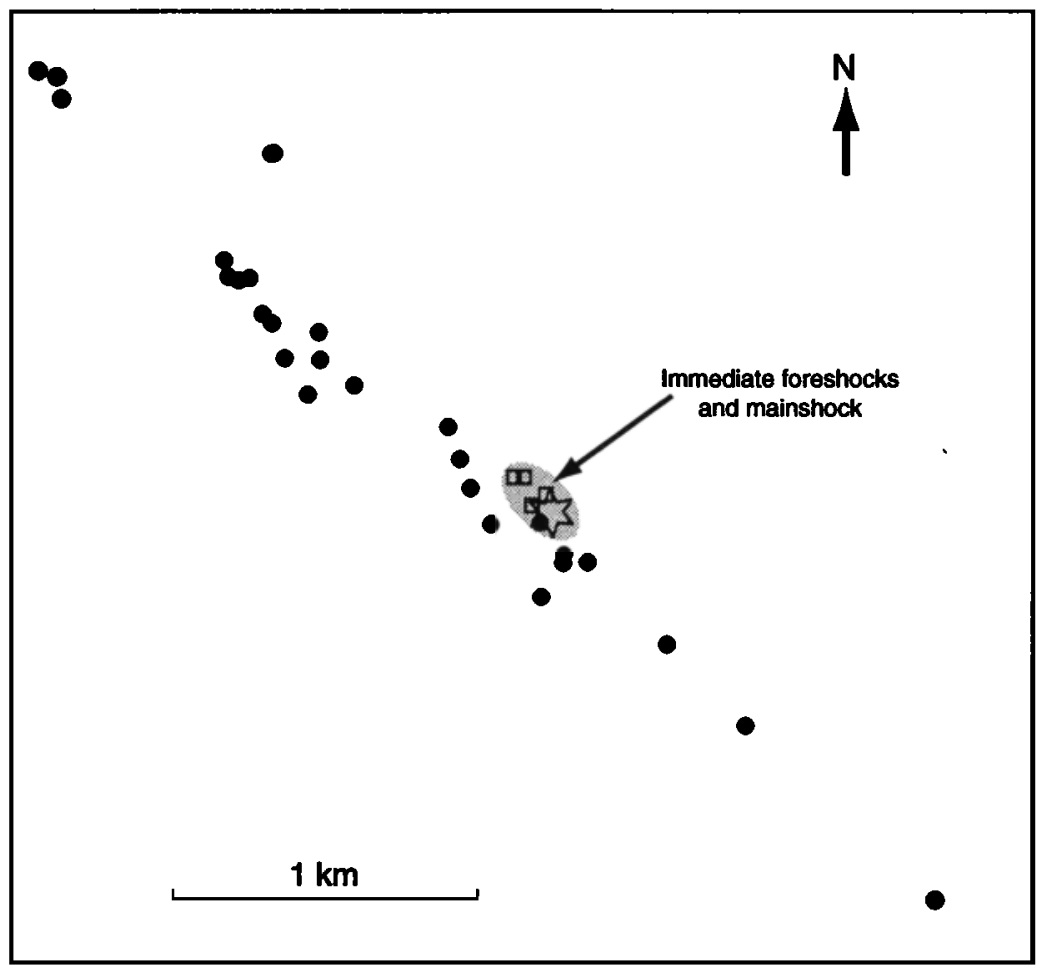

Figure 7. Relocated seismicity in the Stone Canyon epicentral region from July 1984 to May 31,1986 . Stippled region encloses the immediate foreshock and mainshock epicenters. There is no obvious change in strike of the seismicity that might indicate a change in fault strike. The mainshock and immediate foreshocks appear to be shifted somewhat to the NE, but the amount of the shift is of the order of the location uncertainties and could be an artifact.

\section{Map View}

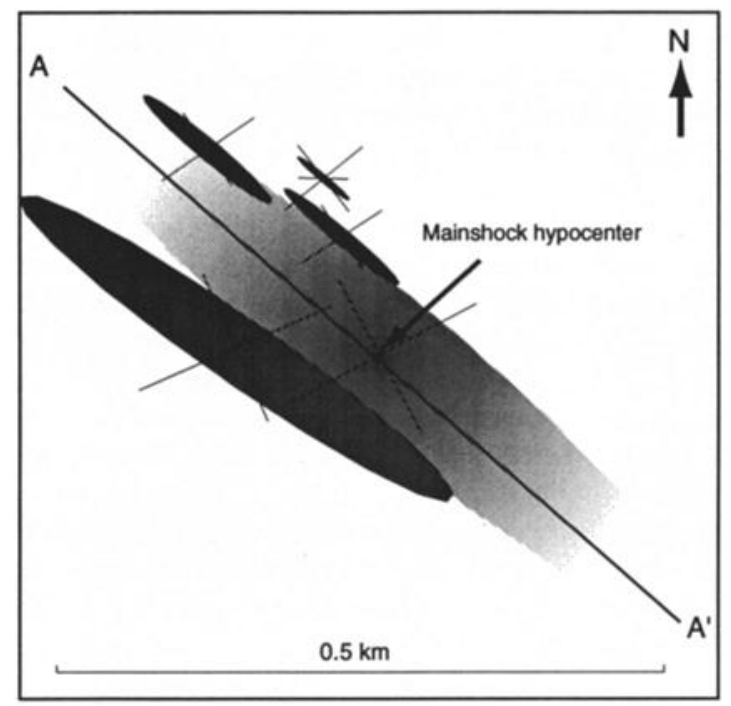

\section{A - A' Cross section}

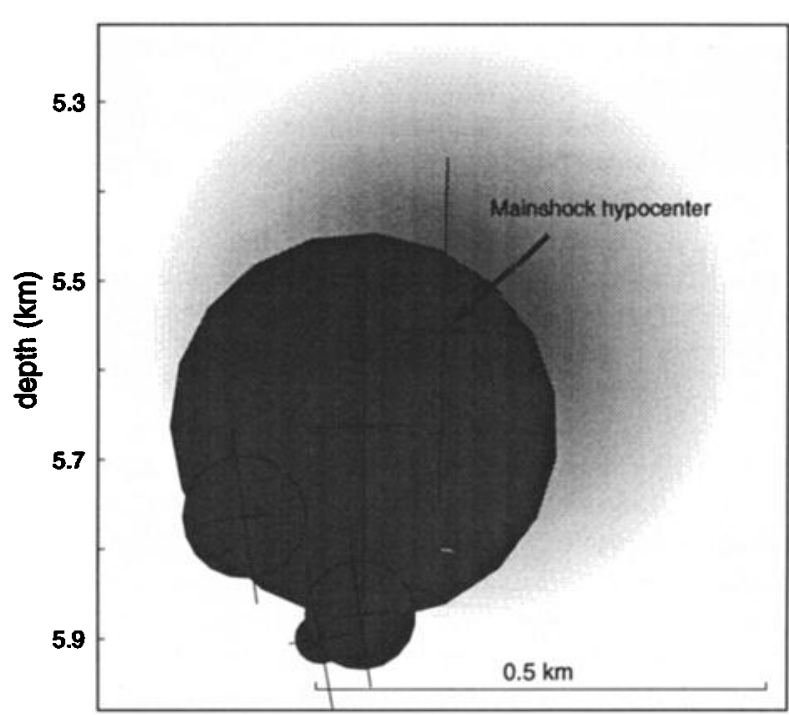

\section{f $95 \%$ confidence limits}

Figure 8. Relocated immediate foreshock and mainshock hypocenters of the Stone Canyon earthquake, (left) map view and (right) cross section looking to the NE. 
Cross section, (Viewing azimuth 30 degrees)

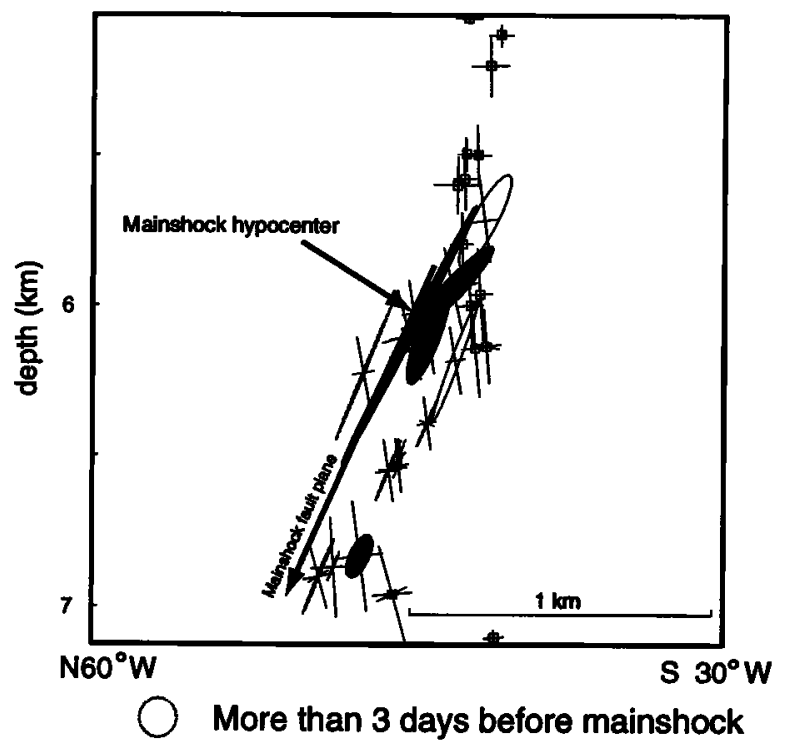

Within 3 days of mainshock

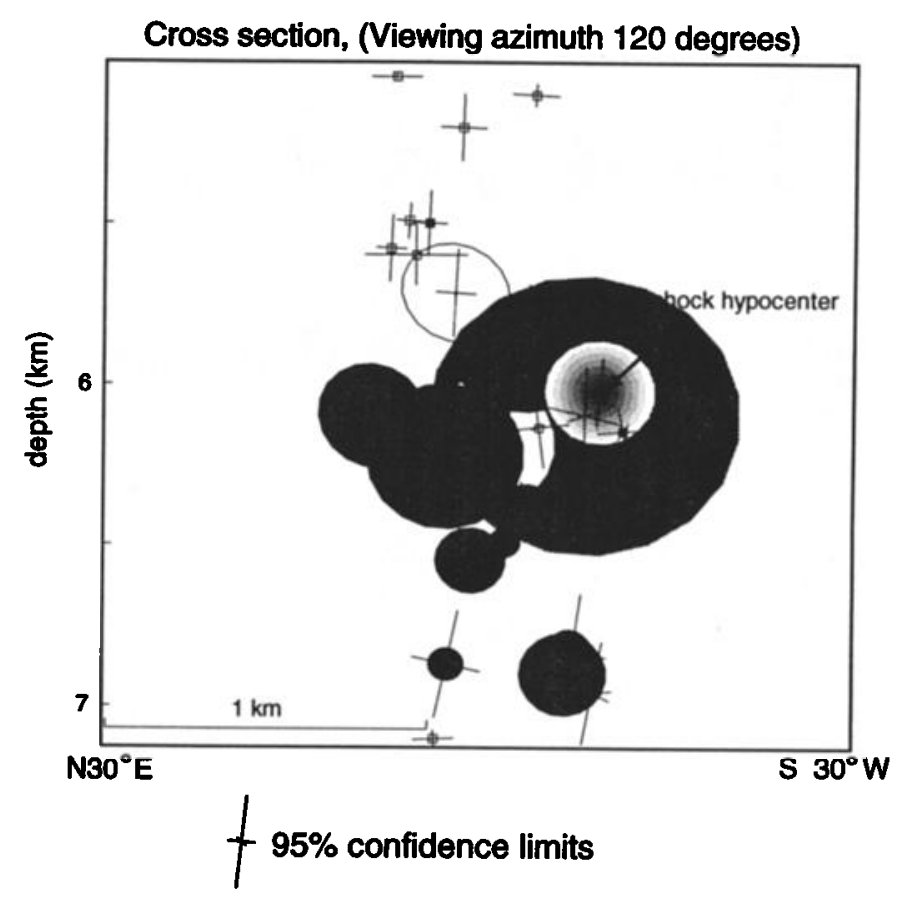

Figure 9. Relocated immediate foreshock and mainshock hypocenters of the Chalfant earthquake in cross sections (left) looking along strike to the NE and (right) perpendicular to the strike looking to the SE. Foreshocks occurring prior to 3 days before the mainshock are shown with open circles. Earthquakes without focal mechanisms are shown as squares.

conjugate fault plane [Smith and Priestley, 1988]. That principal foreshock was itself preceded by $\mathbf{4 0}$ foreshocks within 17 days recorded by the USGS Calnet and University of Nevada, Reno, short-period networks. Of these, 30 had usable waveforms and were analyzed in this study. Most of the Mammoth Lakes stations to the NW of the Chalfant valley are telemetered to Menlo Park. A group of stations immediately to the west and SW is telemetered both to Menlo Park and to Reno. The remaining east and NE stations are telemetered only to Reno. Because there were five shared stations, we were able to use cross correlation to synchronize the two network time bases and merge the data sets, thus providing better constrained solutions than would have been possible using either data set individually.

Figure 9 shows the relocated foreshocks. Figure 9 (left) shows a cross section looking to the NE along the strike of the principal foreshock. Figure 9 (right) is a cross section looking to the SE ( $90^{\circ}$ clockwise relative to the first cross section). The early foreshocks are nearly all shallow, and they appear to form a nearvertical plane. However, this fault geometry cannot be verified from the focal mechanisms since these events were mostly too small to determine well-constrained focal mechanisms. The later foreshocks nearly all dip to the NW at about $60^{\circ}$ and are as deep as or deeper than the principal foreshock. The two early events for which we calculated focal mechanisms dip to the NW at about $60^{\circ}$, much the same as the later foreshocks. The later foreshocks appear to define two subparallel fault strands. The principal foreshock is offset about $400 \mathrm{~m}$ to the SW from most of the other foreshocks. However, the largest of the foreshocks to the principal foreshock, a $M_{L}=3.9$ event, is nearly collocated with the principal foreshock hypocenter. This foreshock sequence appears to be another example of earthquake nucleation at a fault zone irregularity. The principal foreshock hypocenter is at a depth of about $6 \mathrm{~km}$, the depth where the change in dip (based on seismicity) occurs. Nearly all the large foreshocks of the sequence occurred within $250 \mathrm{~m}$ of that apparent change in dip.

\section{Upland Sequence}

The 1990 Upland, California, earthquake $\left(M_{L}=5.2\right)$ was a predominantly left-lateral, strike-slip earthquake that occurred on the San Jose fault [Hauksson and Jones, 1991]. This was the second of a pair of moderate earthquakes that occurred at nearly the same location within two years of each other. The first was a $M_{L}=4.6$ event that occurred about two $\mathrm{km}$ to the southwest and about $4 \mathrm{~km}$ deeper, also apparently on the San Jose fault [Hauksson and Jones, 1991]. The 1990 earthquake was preceded by three foreshocks on the same day, as well as by four other foreshocks that occurred within 20 days prior to the mainshock. The relocated seismicity is shown in Figure 10. The foreshock sequence is distinguished from the other sequences examined in this study in that although the foreshocks were tightly clustered, their hypocenters were well removed ( $>2 \mathrm{~km}$ ) from the mainshock hypocenter. It is difficult to infer much about the geometry of the San Jose fault in the hypocentral region from the limited data of the foreshock sequence. However, Hauksson and Jones [1991] noted that the dip of the San Jose fault based on aftershocks varies with depth. Above 5-6 km the fault dips about $70^{\circ}$ to the NW. Between $6 \mathrm{~km}$ and $9-10 \mathrm{~km}$ the fault is near vertical, from there to about $12 \mathrm{~km}$ the fault dips about $60^{\circ}$, and below 13 $\mathrm{km}$ the dip is again about $70^{\circ}$. The foreshocks range in depth from about 6.4 to $7.3 \mathrm{~km}$, and the three for which we have focal mechanisms show near vertical dips, consistent with the geometry obtained by Hauksson and Jones [1991]. Most of the aftershocks of the 1988 earthquake occurred at depths greater than $5 \mathrm{~km}$, below the hypocenter of the 1990 earthquake. If the aftershocks outline the part of the fault that slipped coseismically or postseismically, then we might expect that the region above 5 


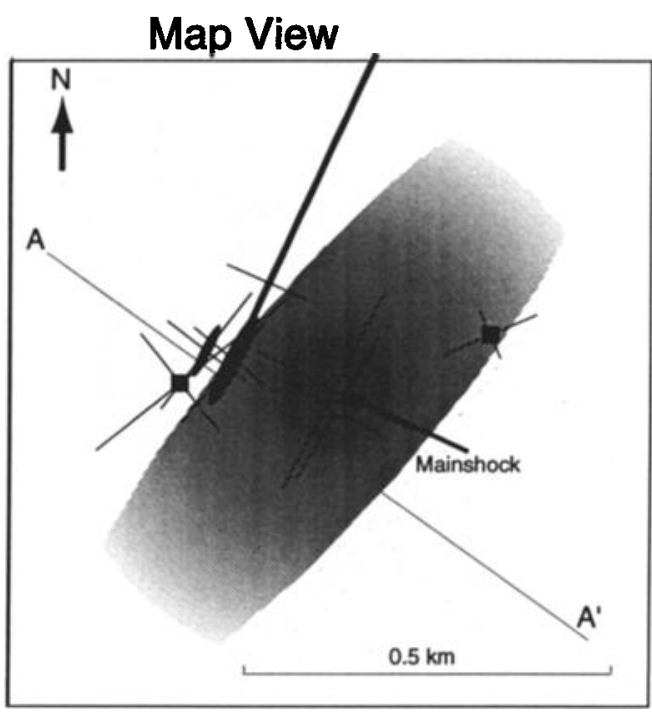

Within 30 days of mainshock

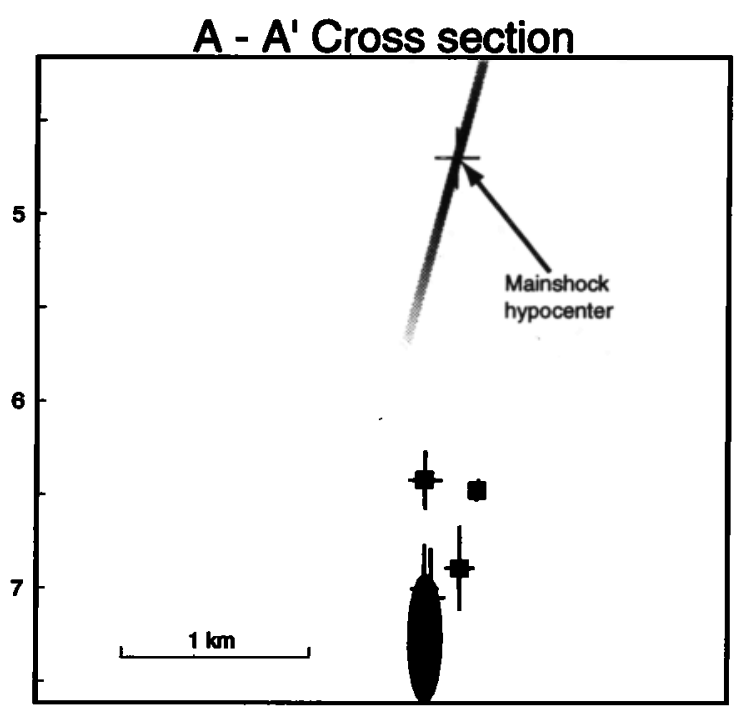

f $95 \%$ confidence limits

Figure 10. Relocated immediate foreshock and mainshock hypocenters of the Upland earthquake, (left) map view and (right) cross section perpendicular to the strike looking to the SE. Earthquakes without focal mechanisms are shown as squares.

km was closer to failure than the deeper part of the fault. Together, these observations suggest that the location of the foreshocks could have been controlled both by structural complexity of the fault zone (the transition from steeply dipping to vertical to shallow dipping) and by stress concentration from the earlier event.

\section{Joshua Tree Sequence}

The 1992 Joshua Tree, California, earthquake $\left(M_{W}=6.1\right)$ was the first large earthquake of the Landers, California, earthquake sequence. It occurred about $10 \mathrm{~km}$ east of the San Andreas fault and $20 \mathrm{~km}$ south of the Pinto Mountain fault. The hypocenter was at about $10 \mathrm{~km}$ depth, and there was no associated surface rupture [Hauksson et al., 1993]. The mainshock was preceded by five foreshocks within 2.4 hours, the first of which had a magnitude of 4.6. Figure 11 shows the relocated mainshock and foreshock hypocenters. Prior to the foreshocks there had been almost no earthquakes within $2 \mathrm{~km}$ of the epicenter since at least 1982. The $M_{L}=4.6$ foreshock hypocenter was about $300 \mathrm{~m}$ from the mainshock hypocenter, and the focal mechanisms were both right-lateral on a plane striking $345^{\circ}$. This relative location is based on first-break times since seismograms of both the principal foreshock and the mainshock are clipped at all nearby stations.

\section{Landers Sequence}

The 1992 Landers, California, earthquake $\left(M_{W}=7.3\right)$ was the largest earthquake in the sequence that began with the Joshua Tree foreshocks. The Landers earthquake occurred on June 28 , approximately 2 months after the Joshua Tree earthquake. The mainshock initiated with a magnitude 4.4 sized immediate foreshock [Abercrombie and Mori, 1994] before propagating $\sim 70 \mathrm{~km}$ along strike to the northwest [Cohee and Beroza, 1994]. The epicenter was about $30 \mathrm{~km}$ north-northwest of the Joshua Tree epicenter. The Landers earthquake was preceded by 27 foreshocks that occurred within 7 hours of the mainshock and within about $1.5 \mathrm{~km}$ of the mainshock hypocenter. There were an additional three events that occurred between the date of the Joshua Tree mainshock and June 28 that were located within 2 km of the Landers epicenter.

Figure 12 shows the relocated foreshocks. This is similar to Dodge et al. [1995, Figure 9] but uses locations made using the technique discussed in this paper. Figure 12 (left) is a map view, and Figure 12 (right) is a cross section looking to the $\mathrm{NE}$ perpendicular to the strike of the seismicity. The three foreshocks occurring before the day of the mainshock are shown unshaded. Foreshocks without focal mechanisms are shown as squares. All others are shown as oriented disks. The sequence extends about $1.7 \mathrm{~km}$ along the fault and about $1.5 \mathrm{~km}$ in depth. The foreshock epicenters define an approximate $500-\mathrm{m}$ jog near the mainshock hypocenter. The existence of the jog is supported by the focal mechanisms, which show a systematic rotation in strike through the jog. Virtually all the moment release of the foreshock sequence is concentrated around the jog. The largest foreshock $\left(M_{L}=3.6\right)$ is nearly collocated with the mainshock hypocenter.

\section{Stress Change Calculations}

The next step in analyzing the mechanics of these foreshock sequences is to use our knowledge of the foreshock hypocentral parameters to attempt to discriminate between models of foreshock generation. We consider two models; a cascade model and a preslip model. In the cascade model (Figure 13a) an initial event triggers a sequence of events that culminate in the mainshock. Events in the sequence cause the occurrence of later 
Map View

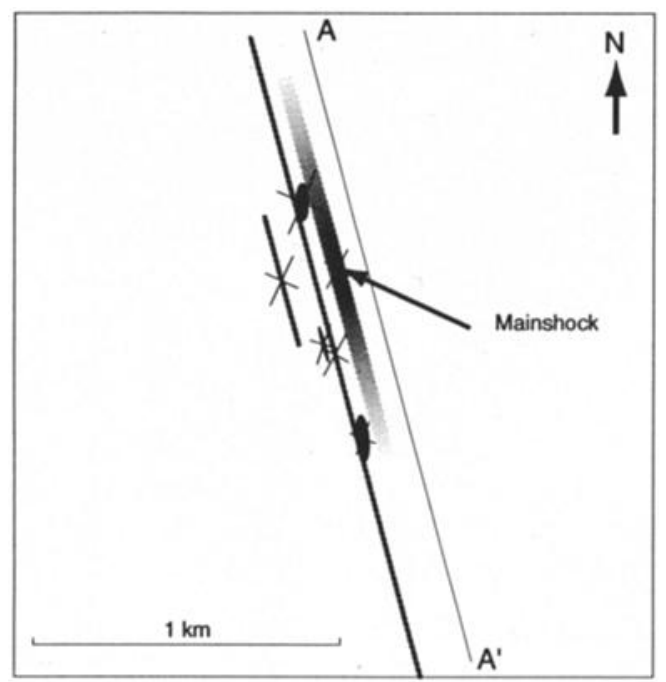

A - A' Cross section

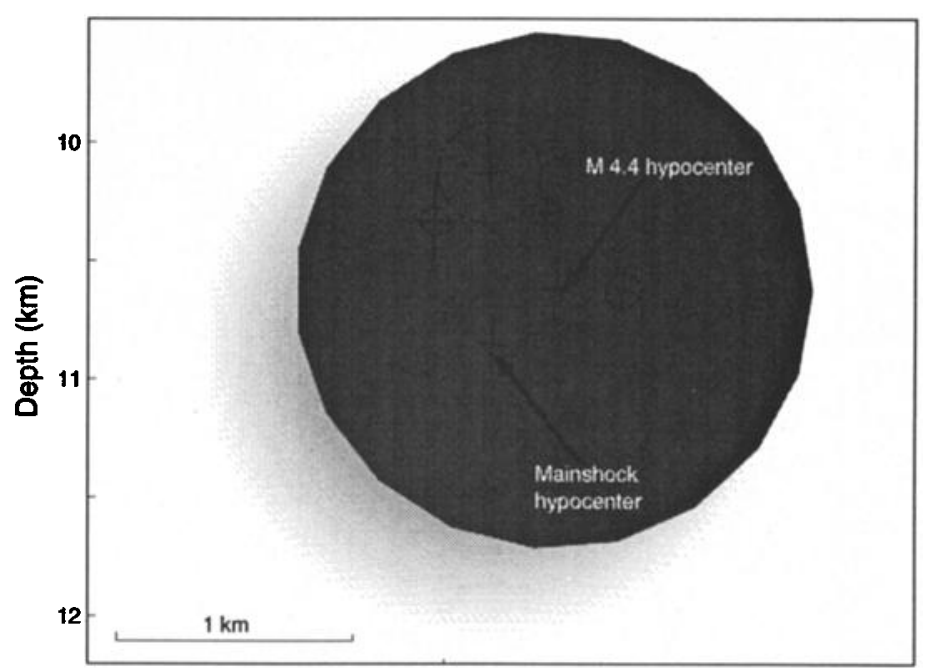

\section{f $95 \%$ confidence limits}

Figure 11. Relocated immediate foreshock and mainshock hypocenters of the Joshua Tree earthquake, (left) map view and (right) cross section parallel to the strike looking to the NE. The largest foreshock has a focal mechanism very similar to that of the mainshock and is nearly collocated with the mainshock hypocenter.

events. In this view, big and little earthquakes start out the same way. The triggering might be directly through the static stress changes [Jones, 1984], indirectly through pore pressure changes [Jones et al., 1982], or perhaps through dynamic effects. In the preslip model (Figure 13b), nucleation is fundamentally an aseismic process involving quasi-static creep over a nucleation region. In this model, foreshocks are interpreted as localized failure within the aseismically slipping nucleation zone [e.g. Das

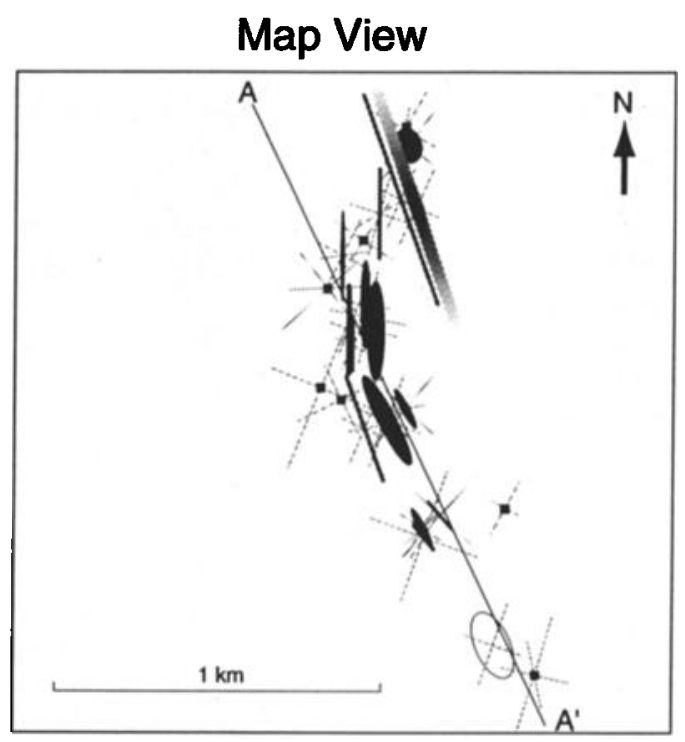

More than 30 days before mainshock

\section{Within $\mathbf{3 0}$ days of mainshock}

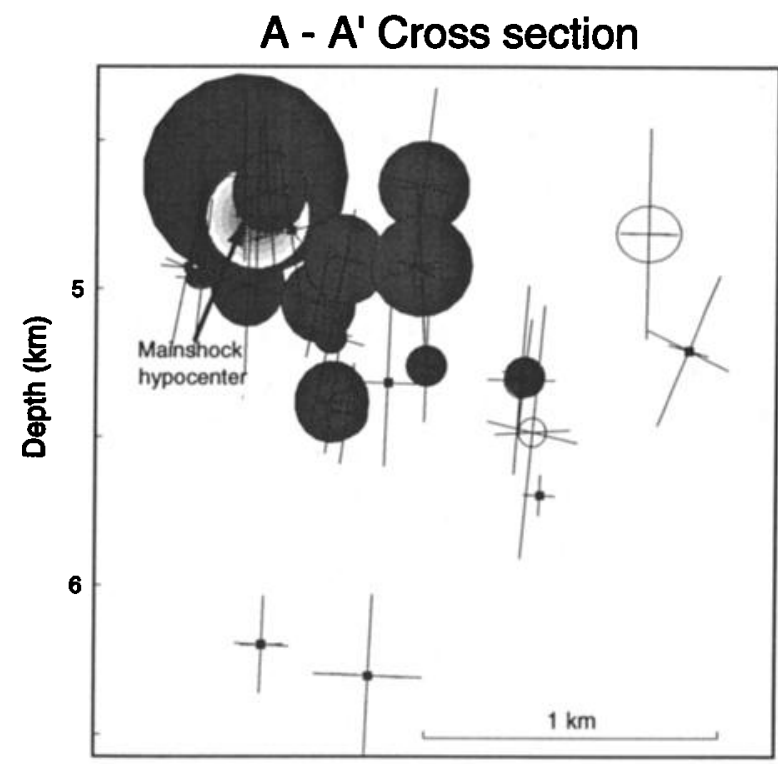

$$
\text { f } 95 \% \text { confidence limits }
$$

Figure 12. Relocated immediate foreshock and mainshock hypocenters of the Landers earthquake, (left) map view, and (right) cross section parallel to the strike of the sequence looking to the NE. In map view a pronounced right step is visible in the seismicity. The step is associated with a clockwise rotation of focal mechanisms. The largest foreshock has a focal mechanism very similar to that of the mainshock and is nearly collocated with the mainshock hypocenter 
(a) Slow Cascade
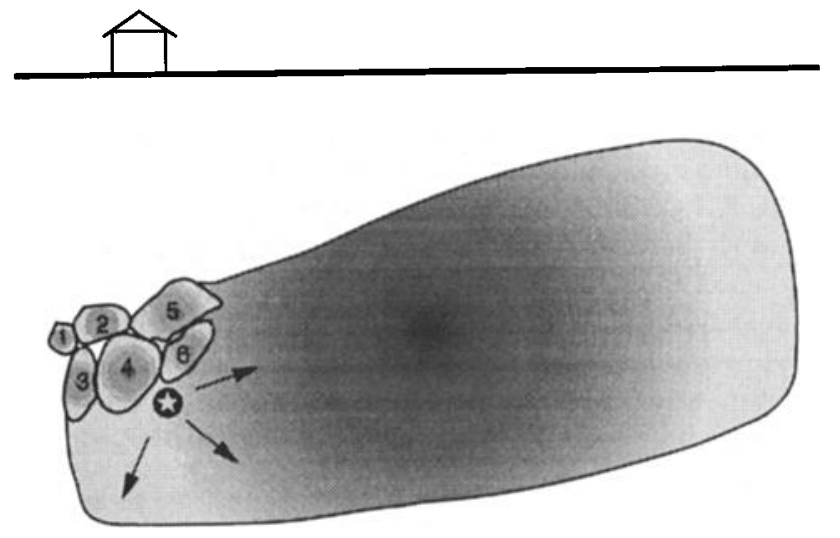

(b)Preslip Triggering
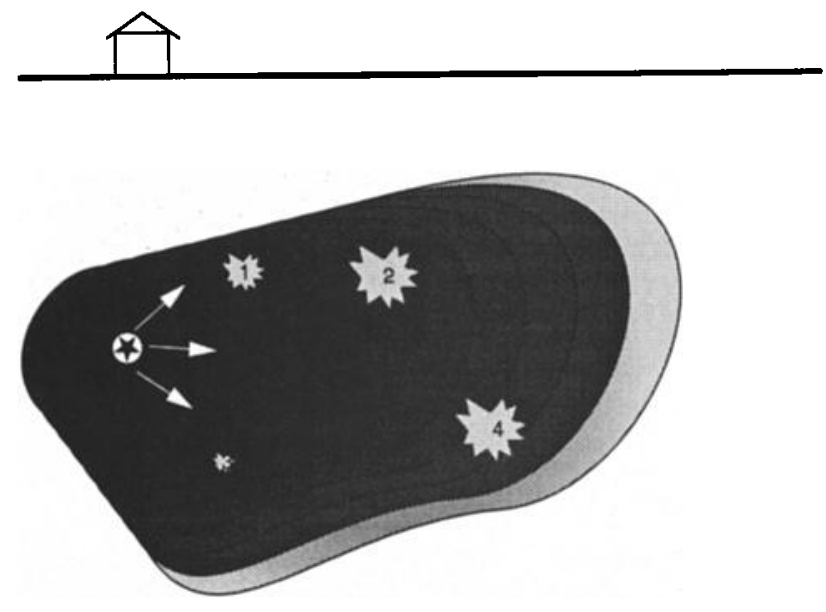

Figure 13. Schematic depiction of two possible mechanisms for foreshock generation. (a) Foreshocks triggered by previous foreshocks load the point of the eventual mainshock in a cascade of failure. (b) Foreshocks occurring at asperities within the nucleation region as the asperities are loaded by creep. Here foreshocks are a byproduct of the nucleation process.

and Scholz, 1981; Ohnaka, 1992]. If the cascade model is correct, then the foreshocks should act to trigger the mainshock, directly through the static stress changes at the mainshock hypocenter, indirectly through increases in pore pressure at the mainshock hypocenter, or through dynamic effects. On the other hand, if the preslip model is correct or if only dynamic effects are important, then the direction and magnitude of the static stress changes at the mainshock hypocenter represent only part of the stress evolution. Our modeling cannot distinguish the presence or absence of dynamic effects, but we can test for static stress changes and subsequent pore fluid changes.

We will model the cumulative stress change at the mainshock hypocenter from all of the foreshocks to see if the stress change is consistent with the mainshock failure mechanism. This type of analysis is commonly used to study fault interactions on a much larger scale [e.g., King et al., 1994; Simpson and Reasenberg, 1994; Harris and Simpson, 1992; Stein et al, 1992]. There are a number of idealizations and uncertainties associated with this calculation. Potentially geometrically complex faults are modeled as one, or a few rectangular planes. An approximation of the actual slip distribution is made. The earth is modeled as an elastic half-space. Many unknown factors affecting the frictional properties of the target fault are lumped into an assumed coefficient of friction. These approximations affect details of the stress change calculations. However, if the target fault is not in a high-gradient part of the stress field, they have little effect on the magnitude or sign of the stress change.

Our relative locations are accurate $(95 \%$ confidence limits less than $100 \mathrm{~m}$ horizontally and $200 \mathrm{~m}$ vertically), but the size of the foreshock zones is only of the order of $1 \mathrm{~km}$. Thus errors in hypocentral parameters could, in some cases, induce significant errors in calculated stress. We account for those errors by mapping the hypocentral uncertainties into distribution functions for the stress changes on the mainshock hypocenters. For each sequence we estimate the effect of the foreshocks on the mainshock initiation by modeling the cumulative stress change induced at the mainshock hypocenter by the foreshocks. Each foreshock is modeled as a square dislocation with area equal to that of a circular patch of radius $r$ [Keilis-Borok, 1959]

$$
r=\left(\frac{7 M_{0}}{17 \Delta \sigma}\right)^{1 / 3}
$$

and displacement

$$
\Delta \bar{\mu}=\frac{M_{0}}{A \mu} .
$$

Here $\Delta \bar{\mu}$ is the displacement, $M_{0}$ is the seismic moment, $\Delta \sigma$ is the static stress drop, $A$ is the area that slipped, and $\mu$ is the shear modulus. We estimate $M_{0}$ from the earthquake magnitude $M$ using the empirical relation [Kanamori and Anderson, 1975]

$$
M_{0}=10^{(1.5 M+9.05)} \text {. }
$$

The locations of the foreshock hypocenters $\left(x_{s}, y_{s}, z_{s}\right)$ are from our relocations, and the orientations of the foreshock fault planes and slip vectors $\left(\phi_{s}, \delta_{s}, \lambda_{s}\right)$ are determined using the FPFIT program [Reasenberg and Oppenheimer, 1985]. Only foreshocks of at least magnitude $\mathbf{2 . 0}$ are used since smaller events have little effect on the stress field and since the smaller events usually do not have well-constrained focal mechanisms. These data, $\left(x_{s}, y_{s}, z_{s}, A, \Delta u, \phi_{s}, \delta_{s}, \lambda_{s}\right)$ are used to calculate the Stress-change tensor at the mainshock hypocenter $\left(x_{m}, y_{m}, z_{m}\right)$ using a method developed by Okada [1992]. From that we obtain the shear stress change in the direction of the mainshock slip vector $\Delta \tau_{s}$, the normal stress change at the mainshock hypocenter $\Delta \sigma_{N}$, and the mean stress change at the mainshock hypocenter $\Delta \sigma_{m}$, where

$$
\Delta \sigma_{m}=\Delta \sigma_{k k} / 3
$$

The Coulomb stress change $\Delta \sigma_{c}$ due to one foreshock at the mainshock hypocenter is

$$
\Delta \sigma_{c}=\Delta \tau_{s}-\mu_{f}\left(\Delta \sigma_{N}-\Delta p\right)
$$

Here $\mu_{f}$ is the coefficient of friction for dry rock and $\Delta p=-B \Delta \sigma_{m}$ is the pore pressure change at the mainshock hypocenter assuming undrained conditions. $B$ is Skempton's coefficient, an elastic constant introduced by Biot theory that is a combination of modulii for undrained and drained deformation. $B$ ranges from 0.51 for Tennessee marble to 0.88 for Rhur sandstone [Rice and Cleary, 1976]. The exact value of $B$ used does not influence our results much since the mean stress changes 
are relatively small. We used a value of 0.8 . The cumulative Coulomb stress change due to a sequence of $M$ foreshocks is

$$
\Delta S_{c}=\sum_{i=1}^{M}\left[\Delta \tau_{s}^{i}-\mu_{f}\left(\Delta \sigma_{N}^{i}-\Delta p^{i}\right)\right]
$$

If our data were exact, this point estimate of the stress change would be the true stress change. However, although our relocations and focal mechanism determinations are very accurate, their uncertainties are significant relative to the dimensions of the sequence. If the mainshock hypocenter is in a high-gradient part of the stress field, then small errors in location, mechanism, or event size may cause large changes in the value or even the sign of the calculated Coulomb stress. To properly account for the effect of the uncertainties, we treat our data $\left(x_{s}, y_{s}, z_{s}, A, \Delta u, \phi_{s}, \delta_{s}, \lambda_{s}, x_{m}, y_{m}, z_{m}, \phi_{m}, \delta_{m}, \lambda_{m}\right)$ as random variables mapped through the stress-change calculations into the random variable $\Delta S_{e}$, for which we estimate the distribution by Monte Carlo simulation [Press et al., 1986]. We assume that the errors in our data are normally distributed with zero mean. For the hypocenter locations the distribution of each variable is centered on its nominal value and the variance of its distribution is taken from the solution covariance. The variance of each focal mechanism parameter is taken as the squared parameter uncertainty from the FPFTT program. Stress drops are assumed to be distributed lognormally with a mean of $3.0 \mathrm{MPa}$ and with $99 \%$ of the values between 0.1 and $100 \mathrm{MPa}$. From the stress drop distribution and magnitude we obtain distributions of foreshock size $A$ and slip $\Delta \bar{\mu}$. To account for the focal plane ambiguity in the focal mechanisms, we generate another random variable uniformly distributed between -1 and +1 and choose the focal plane and rake based on the sign of this random variable. Figure 14 shows an example set of data distributions generated using this approach.

Figure 15 shows the simulation results for the six foreshock sequences. For each sequence the shear traction change, normal traction change, Coulomb stress change $(\mu=0.6)$, and the pore pressure change distributions are shown. Of the six sequences,
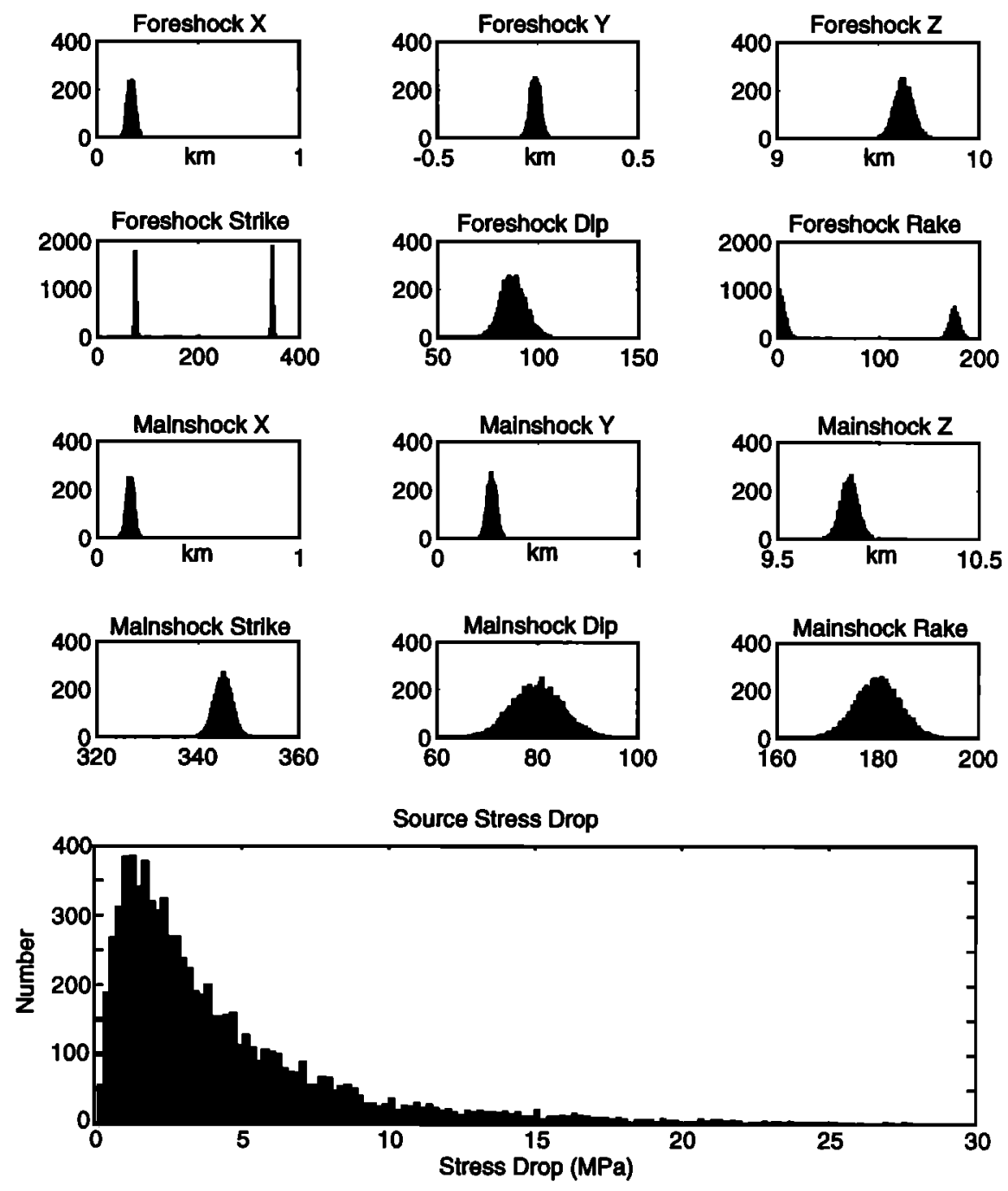

Figure 14. Sample of input parameter distributions for stress-change modeling. (top to bottom) Distributions for the source event coordinates, distributions for the source focal mechanism parameters (the bimodal character of the strike and rake distributions is intended to account for the focal-plane ambiguity in the focal mechanism determinations), corresponding distributions for the mainshock hypocenter (the focal mechanism ambiguity is considered to be resolved for the mainshock, so its strike and rake distributions are unimodal), and distribution for source stress drop. 
Mt Lewis

Shear Traction Increase Distribution at Mainshock Hypocenter

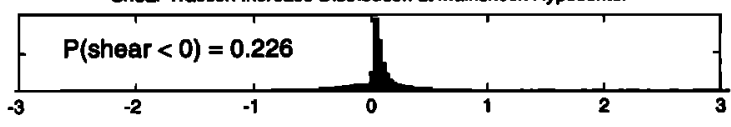

Normal Traction Increase Distribution at Mainshock Hypocenter

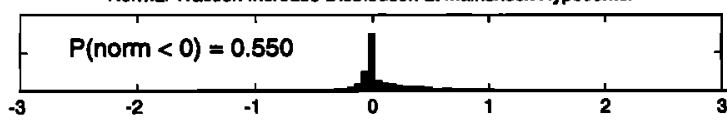

Coulomb Stress Change for $\mu=0.6$

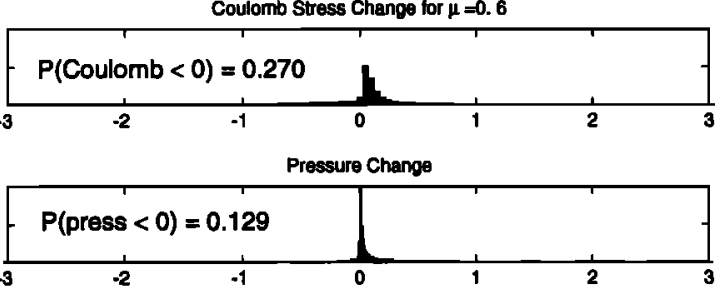

Stone Canyon

Shear Traction Increase Distribution at Mainshock Hypocenter

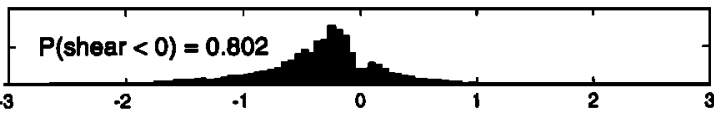

Normal Traction Increase Distribution at Mainshock Hypocenter

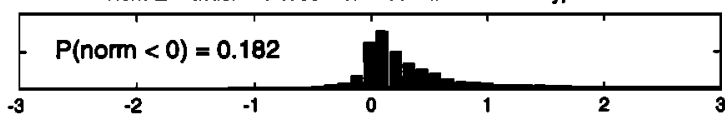

Coulomb Stress Change for $\mu=0.6$

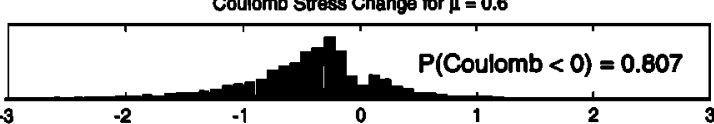

Pressure Change

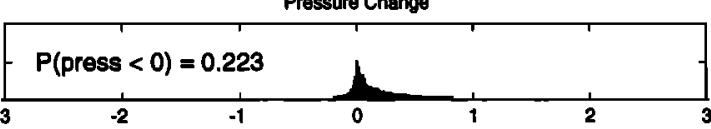

Chalfant

Shear Traction Increase Distribution at Mainshock Hypocenter

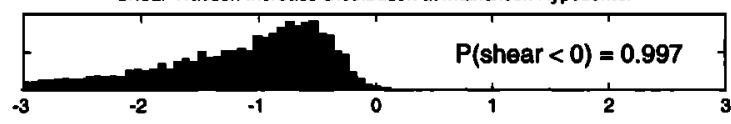

Normal Traction Increase Distribution at Mainshock Hypocenter

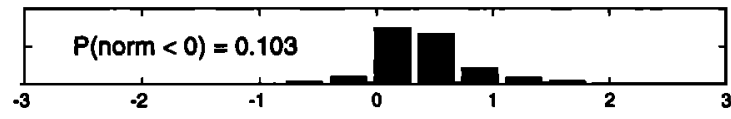

Coulomb Stress Change lor $\mu=0.6$

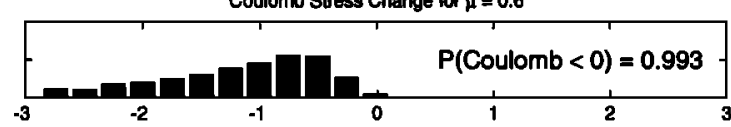

Pressure Change

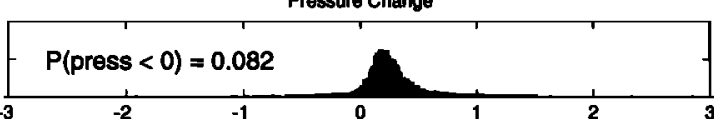

Upland

Shear Traction Increase Distribution at Malnshock Hypocenter

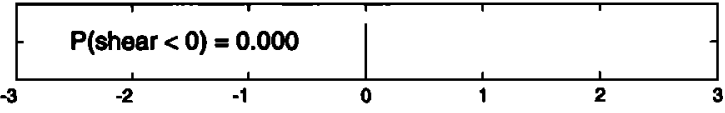

Normal Traction Increase Distribution at Mainshock Hypocenter

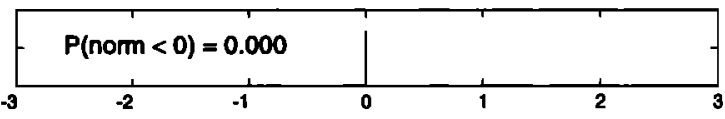

Coulomb Stress Change for $\mu=0$.

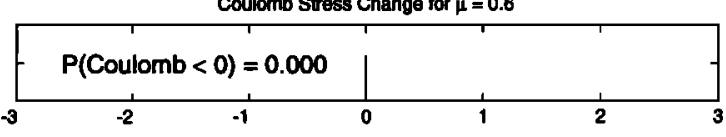

Pressure Change

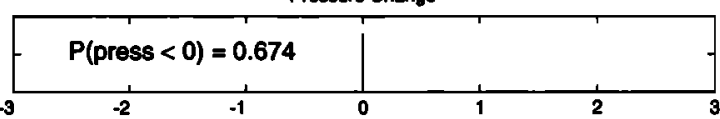

Joshua Tree

Shear Traction Increase Distribution at Mainshock Hypocenter

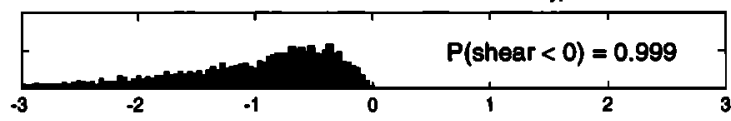

Normal Trection Increase Distribution at Mainshock Hypocenter
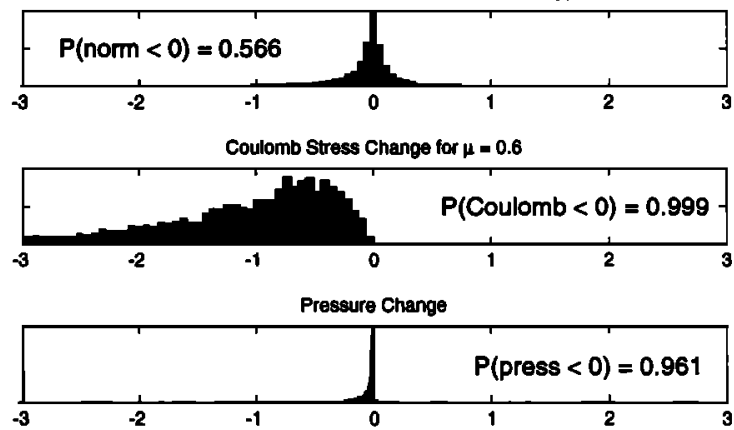

\section{Landers}

Shear Traction Increase Distribution at Mainshock Hypocenter

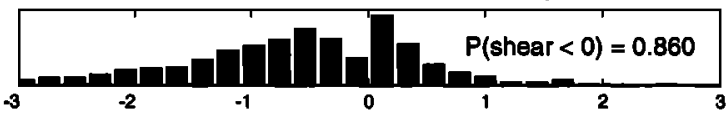

Normal Traction Increase Distribution at Mainshock Hypocenter

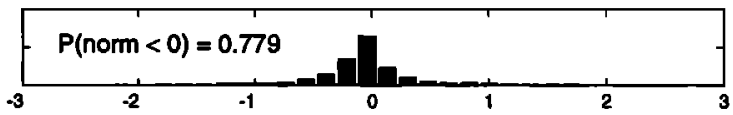

Coulomb Stress Change for $\mu=0.6$

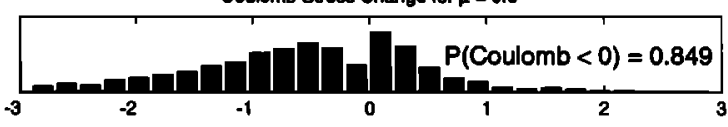

Pressure Change

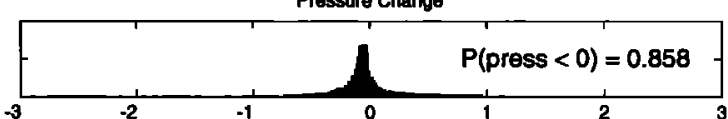

\section{All stresses in $\mathrm{MPa}$}

Figure 15. Stress-change distributions for the six sequences. (top to bottom) The shear traction change distribution, the normal traction change distribution, the Coulomb Stress-change distribution, and the pore pressure change distributionfor each sequence. The sign conventions are such that positive shear contributes to failure, negative normal traction contributes to failure, positive Coulomb stress contributes to failure, and positive pore pressure change contributes to failure. The probability of the parameter being less than zero is also shown. 
only the Mount Lewis foreshocks are likely to have caused stress changes that would trigger the mainshock. The shear traction change distribution is mostly positive, the normal traction change, although near zero, is 55\% negative (increasing tension), and the pore pressure change distribution is positive. At Stone Canyon the shear traction at the mainshock hypocenter is likely $(80 \%)$ to have decreased and the normal traction is likely (72\%) to have increased. Although there may have been a slight pore pressure increase, it was not sufficient to prevent the Coulomb stress distribution from being mostly negative. At Chalfant the shear traction change was almost certainly negative (99.7\%) and the normal traction almost certainly increased. Although there appears to have been a pore pressure increase of about $0.2 \mathrm{MPa}$, the Coulomb stress change was still negative (99.3\%). At Upland the stress changes were consistent with triggering, but the magnitudes of the stress changes were less than 0.001 MPa. By comparison, maximum tidal stresses are of the order of 0.003 $0.004 \mathrm{MPa}$ [Bodri and lizuka, 1989]. Since no clear evidence exists that tidal stresses trigger earthquakes, we conclude that the stress changes from the foreshocks are unlikely to have been important in initiating the mainshock. At Joshua Tree the shear traction and pore pressure changes were almost certainly negative (99.9\% and $96.1 \%$ ) and the normal traction change is likely to have been near zero. The resulting Coulomb stress change is less than zero (99.9\%). At Landers most of the shear traction distribution was negative (86.0\%). The normal traction and pore pressure are both likely to have decreased (77.9\% and $85.8 \%$ ). The shear traction changes were much larger than the normal traction changes, so the Coulomb stress distribution was mostly negative $(84.9 \%)$ These Coulomb Stress-change results are consistent with the previous point estimates of Dodge et al. [1995] for this earthquake.

\section{Discussion}

For four of the six sequences the sign of the Coulomb stress distribution suggests that the mainshock was not triggered by stress changes from the foreshocks, at least at the $80 \%$ confidence level. At Upland the sign of the Coulomb stress distribution was consistent with triggering, but the stress changes were so small that they were probably unimportant in triggering the mainshock. Only the Mount Lewis foreshocks have Stresschange distributions clearly consistent with triggering of the mainshock by its foreshocks.

Pore fluids can accelerate the growth of cracks in silicates through stress corrosion [Scholz, 1990]. If increases in pore pressure increase the rate of stress corrosion, then even though there was a net stress decrease at Stone Canyon and Chalfant, the foreshocks might have indirectly triggered the mainshock by increasing the rate of stress corrosion. However, whether such a pressure dependence in the stress corrosion rate exists is unknown [Meredith and Atkinson, 1983], and even if it does exist, the Landers and Joshua Tree foreshock sequences caused the pore pressure to decrease at their mainshock hypocenters. For these sequences, no triggering mechanism involving static stress changes or pore fluid changes seems appropriate.

It may be that the relation of foreshocks to the mainshock is extremely variable and that some of the time, foreshocks trigger the mainshock and some of the time they do not. That possibility cannot be rejected based on the results of this study. It is also worth noting that our analysis is for the static effects in an isotropic earth. If, for instance, high- pressure fluid were preferentially communicated through the fault zone, it might trigger the mainshock even though our analysis indicates that should not happen. It is also possible that dynamic stresses from the foreshocks could weaken the fault near the mainshock hypocenter, thereby allowing slip at lower driving stress. Despite these limitations our results suggest that theories of foreshock generation requiring the static stress changes from the foreshocks to trigger the mainshock in a kind of cascading failure are not universally applicable. Apart from the Mount Lewis example, the evidence for this kind of triggering is weak, at best, and the evidence against is strong, particularly in the Joshua Tree example.

Several authors [Das and Scholz, 1981; Dieterich, 1992; Ohnaka, 1992] have proposed that foreshocks are simply a byproduct of an aseismic nucleation process. This viewpoint is based on theoretical modeling and laboratory simulation of earthquake nucleation showing that the dynamic instability is preceded by a period of stable sliding within a small patch around the eventual hypocenter. In these models, foreshocks are incidental to the nucleation process and occur on asperities within the nucleation zone that fail from the load imposed by the ongoing creep around them. If the nucleation zone is homogeneous in strength and stress, there are no foreshocks. Because the foreshocks are incidental to the nucleation process in this model, the stress changes from the foreshocks are not required to have any particular relation to the mainshock failure mechanism. If the fault is planar within the nucleation region, then the static stress changes from the foreshocks at the mainshock hypocenter will likely be consistent with the failure mechanism of the mainshock. For other geometries this need not be the case. Our stress-change observations are consistent with this view of foreshock generation.

If foreshocks are indeed a seismic manifestation of an aseismic nucleation process, then their distribution and kinematics provide constraints on the nucleation process. The distribution of foreshocks would provide information about the size of the nucleation zone and its relation to mainshock magnitude. There is debate about the size of the nucleation zone and whether it is large enough to be observable. Dieterich [1986] concludes that the radius of the nucleation zone will be too small to observe unless the critical slip displacement $D_{c}$ is considerably larger for earthquake faults than for laboratory faults. Ohnaka [1992] models nucleation as taking place at a strength heterogeneity on the fault with the size of the heterogeneity controlling the size of the nucleation zone. In this model, strength increases with distance from the center of the nucleation zone, so that stable slip can occur within the nucleation zone. As slip progresses, the nucleation zone grows until a critical size is reached and dynamic rupture ensues. Ohnaka [1993] used foreshocks of the 1978 IzuOshima earthquake $\left(M_{\mathrm{JMA}}=7.0\right)$ to estimate the size of the nucleation zone. He found that the foreshock zone attained a size of $10 \mathrm{~km}$ and that it expanded with time, as required by his model. However, the foreshock sequence occurred entirely offshore, so that seismograph coverage was less than optimal. Many of the events were located kilometers off the inferred fault trace, so there is question about the accuracy of the estimate. Recent observations of the seismic nucleation phase [Ellsworth and Beroza, 1995], if interpreted in terms of an aseismic nucleation process, yield a nucleation zone that scales with mainshock magnitude, and the size of that zone ranges from 600 to $6000 \mathrm{~m}$ for earthquakes with $M W$ 6.5.

Assuming that the extent of the foreshocks provides at least a rough estimate of the size of the nucleation zone, we can compare our observations of foreshocks to specific predictions of the 
models just mentioned. A straightforward estimate of the foreshock zone size is given by the smallest rectangle that encloses all the hypocenters when they are projected on the mainshock fault plane. Figure 16 shows graphically our estimates of the foreshock sequence dimensions for the six earthquakes examined in this study. The sequences are arranged according to mainshock magnitude along the left side of the figure and are all scaled identically. We fit two rectangles to each sequence. One encloses the hypocenters, and the other encloses all the slipped areas (assuming a $3 \mathrm{MPa}$ stress drop for all events). From the area of each rectangle we calculate the radius of a circle of equal area. These are our estimates of the lower bound for the radius of the region slipping aseismically prior to the mainshock. Figure 16 (right) plots the foreshock zone radii versus mainshock moment. Our two estimates for each earthquake are plotted as squares connected by lines. Also, plotted on the same axes are estimates of the nucleation zone radii versus earthquake moment for 21 earthquakes examined by Ellsworth and Beroza [1995]. Our lower bound estimates are within the $1 \sigma$ boundaries of a least squares fit to their data for all but the Landers earthquake, where both estimates are low. However, since foreshocks may provide only a lower bound to the nucleation zone size, the underestimate at Landers can be explained by invoking aseismic slip over a larger area of the fault than that spanned by the foreshocks. Altematively, if the $M_{W}=4.4$ subevent to the mainshock observed by Abercrombie and Mori [1994] is considered as an immediate foreshock, then the size of the foreshock zone for Landers would very likely increase sufficiently to be consistent with the Ellsworth and Beroza [1995] predictions of nucleation zone size.

In interpreting the apparent relation between foreshock zone dimensions and mainshock size shown in Figure 16, it is important to understand how the limitations of the data analyzed in this study may have affected this result. Obviously, the fewer the number of foreshocks, the harder it is to define the foreshock zone. In the limiting case of one foreshock the area of a rectangle enclosing the hypocenters would be zero, although the area enclosing the rupture might be large. More significantly, if swarms with no mainshock were plotted on the same figure, there would probably be no correlation between swarm dimensions and mainshock magnitude.

If the nucleation zone grows with time, as predicted by the Ohnaka [1992] model, then the size of the foreshock zone should also increase with time. However, since the location of individual foreshocks may be controlled partly by the mechanics of the nucleation process and partly by the location and characteristics of individual asperities, the sequence is not likely to grow outward uniformly, even if the nucleation zone is expanding uniformly. Instead, the foreshock locations may only trend outward. With the few events in the sequences we examine, such a trend could easily be masked by the "noise" from the asperity distribution. Abercrombie et al. [1995] examined the Landers foreshock sequence looking for indications of expansion with time and found that for the immediate foreshocks there was some indication that the zone of foreshocks expanded with time at a rate of about 5 to $10 \mathrm{~cm} / \mathrm{s}$, but this interpretation depended partially on treating one of the event locations as an outlier, an assumption that is not absolutely required by the observations.

To search for possible growth of the foreshock sequences with time, we examine two possible measures of growth, the RMS distance from the sequence centroid versus time and the RMS distance from the mainshock hypocenter versus time. Plots of these quantities are shown in Figure 17 for the Chalfant, Landers, and Mount Lewis sequences, the three sequences with enough events that a trend might be meaningful. Figure 17 (left) shows distance from the centroid versus time, and Figure 17 (right) shows distance from the mainshock hypocenter versus time. In each plot a least squares fit line is shown as well. Chalfant and Landers show a slight growth with time, as indicated by the upward slope of the lines in the left-hand plots, but the apparent growth is not statistically significant $(R=-0.15, R=-0.17)$. Both of these sequences show a much stronger trend for the foreshock hypocenters to move toward the mainshock hypocenter with time $(R=0.53, R=0.70)$. The Mt Lewis sequence appears to grow outward with time and shrink toward the hypocenter. The correlation is quite strong for both relations but should be interpreted with caution since the strength of the correlation depends entirely on two points. These results suggest that there may be more of a tendency for the foreshock zone to shrink toward the mainshock hypocenter than to grow outward. This behavior would be consistent with observations of Ishida and Kanamori [1978] and with modeling results by Dieterich [1992] showing that for faults with rate- and state-dependent strength, the earthquake nucleation process involves localization of slip to a subpatch, whose dimensions scale with the characteristic slip distance $D_{c}$.

The reason why some earthquakes are preceded by foreshocks and others are not is still unknown, but fault zone heterogeneity may be an important factor. The idea that foreshocks are associated with fault zone heterogeneity goes back to at least Mogi [1963], and there is considerable observational evidence for that association. For instance, Jones et al. [1982] concluded that the 1975 Haicheng earthquake $\left(M_{L}=7.3\right.$ ) probably nucleated at an en echelon fault step. Jones [1984] showed that of seven California earthquakes with foreshock sequences, four were associated with fault zone discontinuities and the other three were possibly associated with fault zone discontinuities. Lindh et al. [1978] observed a change in $P / S V$ ratios between foreshocks and aftershocks for three California earthquakes that they attributed to a systematic change in stress or fault orientation in the source region. There is a strong inverse relation between depth of mainshock and foreshock sequence duration [Jones, 1984], which was attributed to the increase in minimum compressive stress with depth. In a more recent study, Abercrombie and Mori [ 1995] observed a similar decrease in number of foreshocks with depth and a dependence on focal mechanism of the mainshock. They suggested that the inverse relation with depth was due, at least partially, to the decrease in crustal heterogeneity with depth.

We can investigate the relation between crustal heterogeneity and foreshock generation using the results of this study. If we use the deviation of the fault from simple planar structure as a measure of heterogeneity, we can look for a relation between the amount of deviation and the number of foreshocks. There are a number of potential pitfalls with this approach. For instance, our measure of heterogeneity will not account for all sources of strength and stress variations, there may not be enough foreshocks to define the geometry of the fault, the number of foreshocks recorded might be biased because of differences in network sensitivity, and the choice of temporal and spatial windows used to identify immediate foreshocks could bias the results. Thus any relation that emerges from this analysis must be regarded as being suggestive rather than definitive.

We think that differing network sensitivities are unlikely to have biased our results. The seventh row of Table 1 shows the number of foreshocks recorded by the networks for each mainshock, and the bottom row shows the average distance from the 
Stone Canyon $\mathrm{M}=4.7$

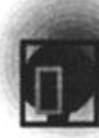

Upland $\mathrm{M}=5.2$

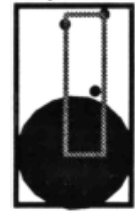

Mt. Lewis $M=5.7$

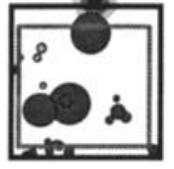

Chalfant $M=5.8$

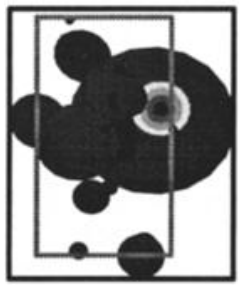

Joshua Tree $M=6.1$
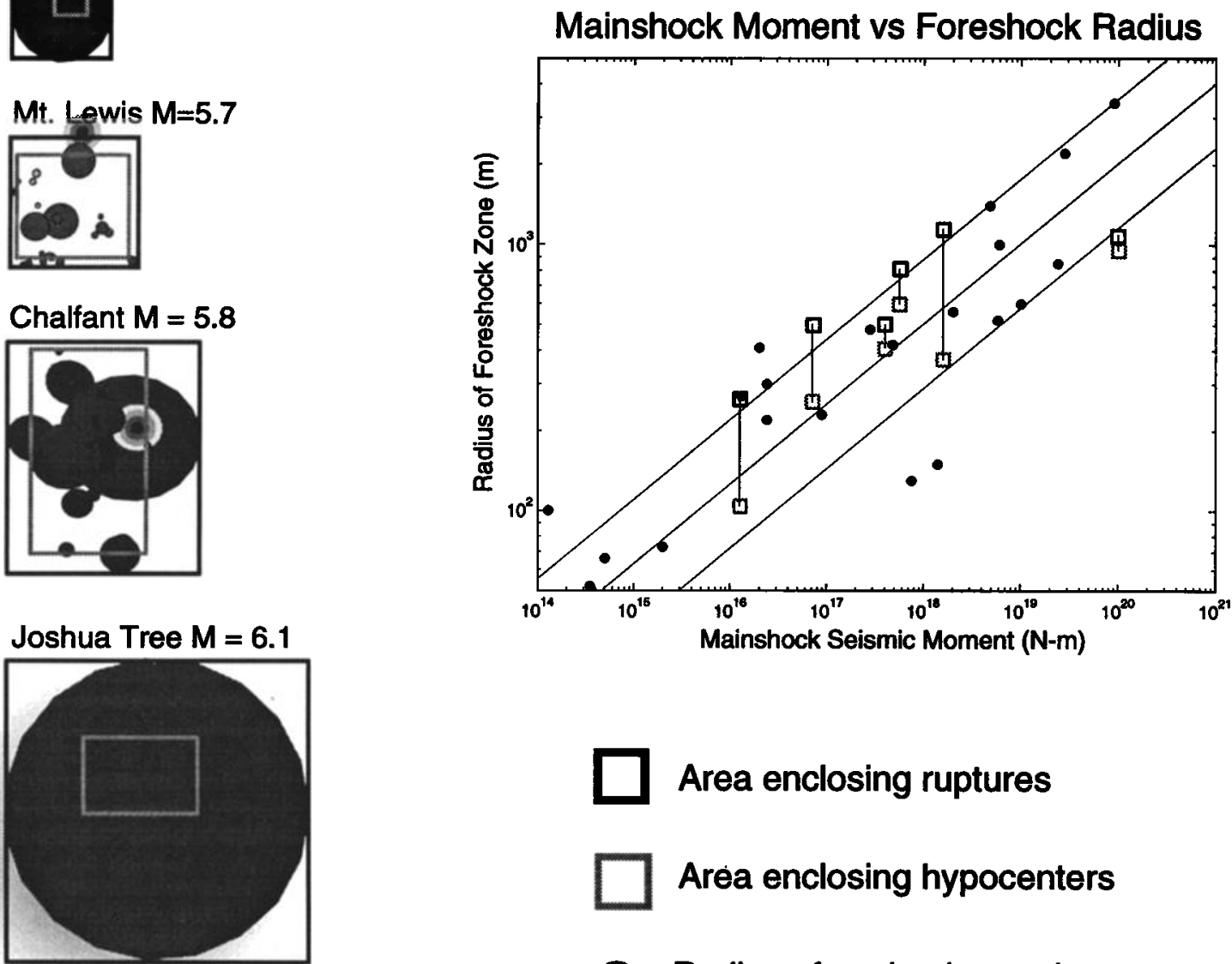

Area enclosing ruptures

Area enclosing hypocenters

Radius of nucleation region

Landers $M=7.3$ from Ellsworth \& Beroza, 1995

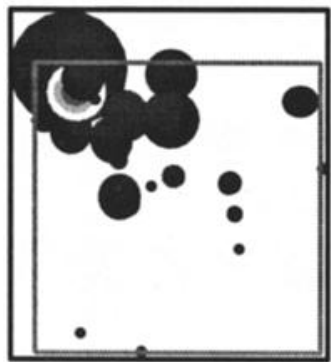

$1 \mathrm{~km}$

Figure 16. Comparison of foreshock zone dimension to mainshock moment. (left) Source disks of the six foreshock sequences projected onto their respective mainshock fault planes (from Figures 7-13). The rectangles superimposed on the plots indicate two ways of measuring the size of the foreshock zones. The outer rectangle encloses the source disks (based on 3-MPa stress drop), and the inner rectangle encloses the hypocenters. From the rectangle areas we calculate the radii of equivalent circles, and these are plotted (right) against mainshock moment. For each event the two estimates of source radius are connected by a line. On the same graph are plotted the estimates of source radius versus mainshock moment from the Ellsworth and Beroza [1995] study of the seismic nucleation phase. The straight lines are a least squares fit to the data and the $1 \sigma$ boundaries from the fit. 


\section{Distance from swarm centroid}
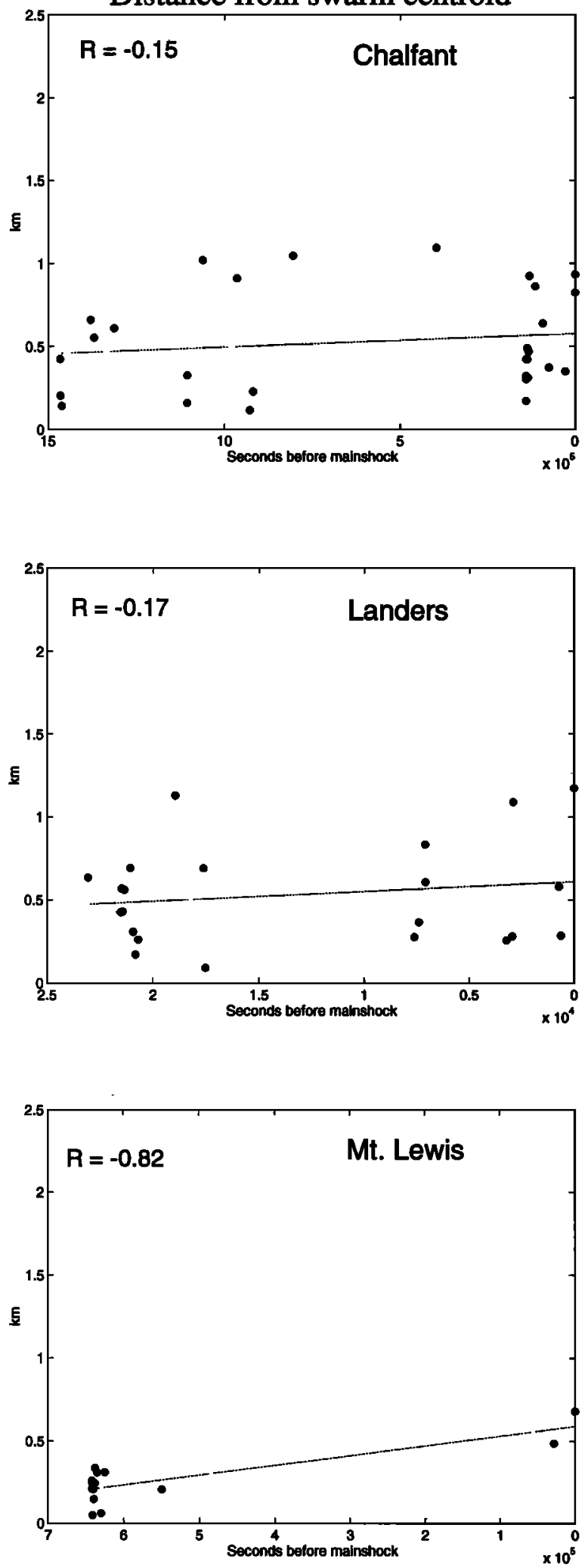
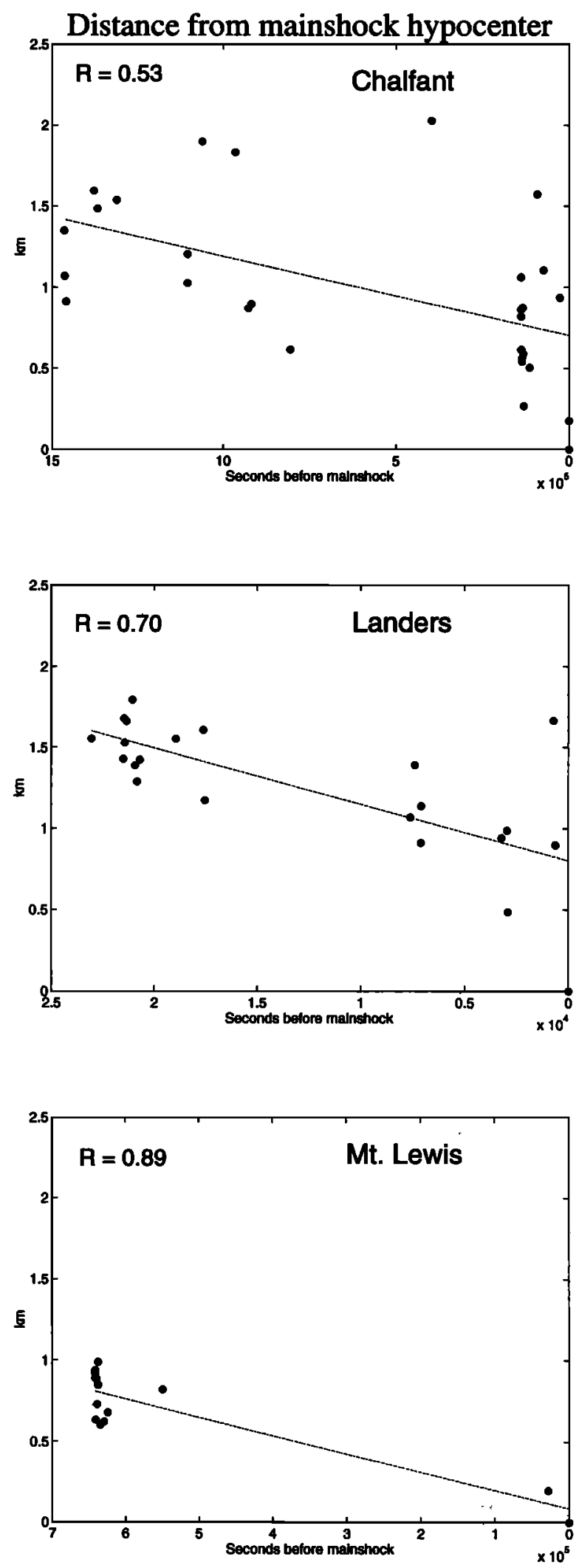

Figure 17. Foreshock sequence evolution with time. (left) distance of the foreshocks from the geometric mean of the foreshock cluster as a function of time before the mainshock. (right) Distance of the foreshocks from the mainshock hypocenter as a function of time before the mainshock. For each plot a least squares fit line to the data is also displayed. Correlation coefficients $R$ are also shown. Only data from the Chalfant, Landers, and Mount Lewis sequences are shown since these are the only sequences with enough foreshocks to clearly define any trends that might exist. 
mainshock of the five nearest stations for each sequence. If the variation in number of events is due to differing station distributions, then the number of foreshocks should be inversely related to average station distance. In fact, smaller numbers do not correspond to larger distances. For instance, the Landers sequence with 30 recorded immediate foreshocks has the greatest average distance, and Stone Canyon with only four immediate foreshocks has the smallest average distance.

All the sequences analyzed in this study were chosen using a spatial window of $2 \mathrm{~km}$ radius. This radius is large enough to avoid not selecting a potential foreshock because of network location error and small enough to avoid including seismicity from most nearby faults. Our results are not very sensitive to increases in this parameter because the distance to the nearest active fault is much greater than $2 \mathrm{~km}$ in all cases.

We used a time window of 30 days prior to the mainshock in our selection of immediate foreshocks. Our results are sensitive to this parameter choice. In the case of Mount Lewis most of the foreshocks we analyzed occurred 7 days before the mainshock, so a time window less than 7 days, for example, would exclude them. In the case of Chalfant the foreshocks occurred over a 3 week period, and a time window shorter than that would change our results.

The results of our comparison are shown in Figure 18. The top portion of the figure shows the immediate foreshocks plotted in a plane perpendicular to the mainshock fault plane. The parallel lines bounding the events in each sequence are drawn parallel to the average focal plane orientation of the foreshocks. Note that one of the Chalfant foreshocks is not enclosed by the lines for that sequence. This event is sufficiently distant from all the other events that there is some question as to whether it is actually part of the sequence. If this event was used, the correlation between fault zone width and number of foreshocks would be stronger. All sequences are plotted at the same scale. The foreshock zone

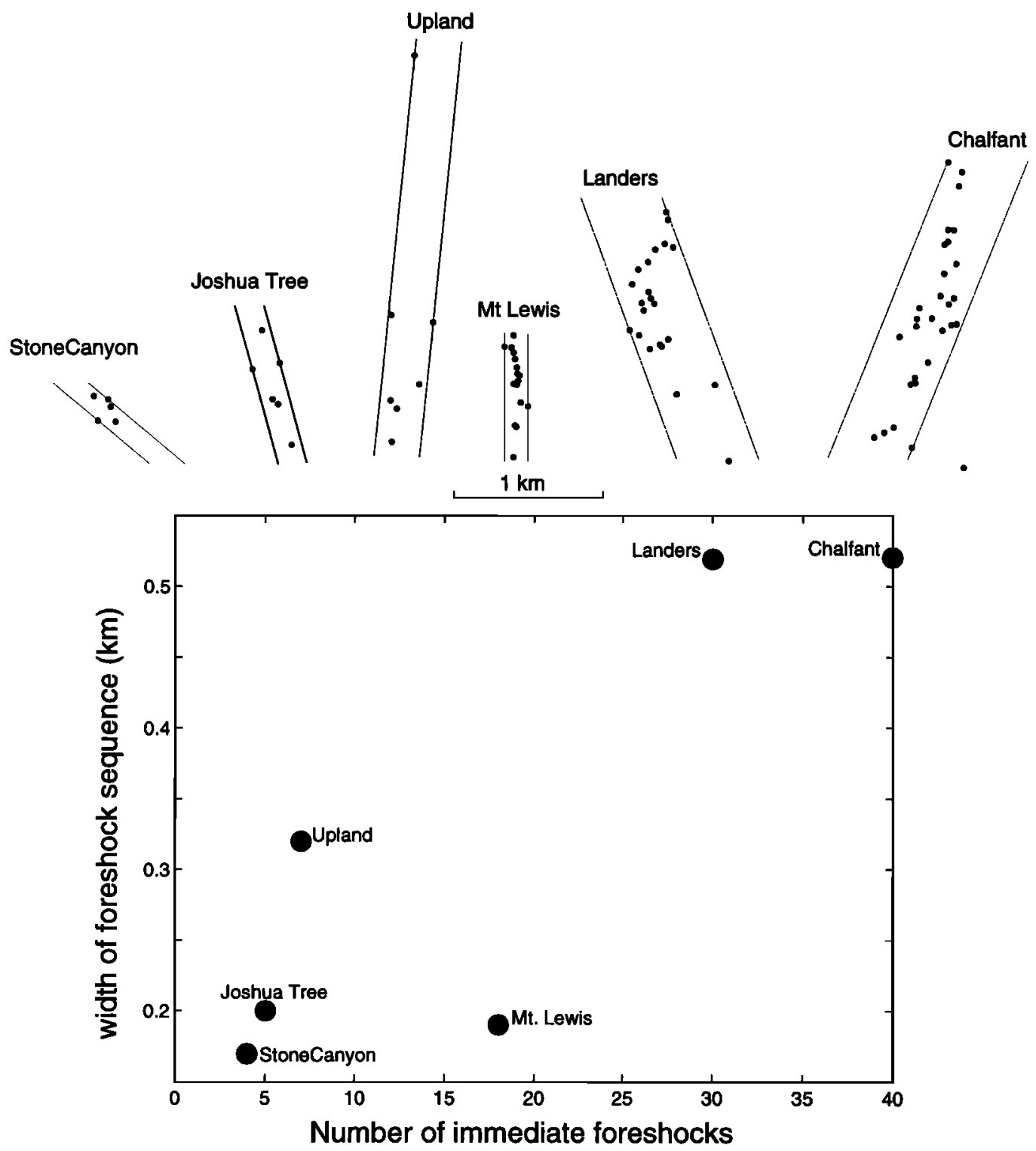

Figure 18. Fault zone width versus number of foreshocks. (top) Immediate foreshocks plotted in a plane perpendicular to the mainshock focal plane. The lines are drawn parallel to the average focal plane orientation of the foreshocks and just far enough apart to enclose all the foreshock and mainshock hypocenters. All sequences are plotted to the same scale. (bottom) Fault zone widths (measured perpendicular to the parallel lines for each sequence) plotted versus number of immediate foreshocks. 
widths are measured perpendicular to the parallel lines for each sequence. Figure 18 (bottom) shows those widths plotted against the number (from the catalog) of immediate foreshocks. With the exception of the Mount Lewis sequence there is a continuous increase of fault zone width with number of foreshocks. The correlation coefficient of the relation is $\mathbf{0 . 8 6}$. Although not definitive, these results certainly suggest that the strength of the heterogeneity is related to the number of foreshocks.

\section{Summary}

We have used high-precision relocations of the foreshock sequences of six California earthquakes to gain insight into the earthquake nucleation process. We find evidence that the foreshocks did not act to trigger the subsequent mainshocks by static stress changes. Of the six sequences, only one (Mount Lewis) had stress changes consistent with static stress triggering. The stress changes from the Upland foreshock sequence were probably too small ( $<0.001 \mathrm{MPa}$ ) to have been important. For the remaining four sequences the Stress-change distributions indicated that the foreshock sequences acted to destress the mainshock hypocenters. These results are consistent with a model in which the foreshocks are incidental to a predominantly aseismic earthquake nucleation process. We find that the size of the nucleation region, measured by the extent of the foreshocks, scales with mainshock moment in the same manner as determined independently by measurements of the seismic nucleation phase [Ellsworth and Beroza, 1995]. Thus we now have two completely independent suggestions that a slow nucleation process precedes some earthquakes. We also find evidence for slip localization, as predicted by some models of earthquake nucleation [Dieterich, 1992]. Fault zone heterogeneity appears to be an important factor in the location of the nucleation zone and in the number of foreshocks produced during nucleation. For three of the six sequences (Mount Lewis, Chalfant, and Landers) the mainshock hypocenter was located within $300 \mathrm{~m}$, at most, of a significant change in strike or dip of the causative fault. The foreshocks to the Upland earthquake were located at a change of dip of the San Jose fault identified by Hauksson and Jones [1991]. Foreshock locations for the Stone Canyon and Joshua Tree earthquakes suggest that multiple fault planes may have been involved, but the scale of the possible heterogeneity is of the same order as the uncertainties in the locations.

Acknowledgments. In this study, we used data recorded by the Southern California Seismic Network (SCSN) (operated jointly by the Seismological Laboratory at Caltech and the U.S. Geological Survey, Pasadena), the Northern California Seismic Network (NCSN) (operated by the U.S. Geological Survey, Menlo Park), and the University of Nevada, Reno. We thank Diane dePolo for her help in obtaining seismograms for the Chalfant foreshocks from the UNR archives and Ken Smith for his help with focal mechanisms for the Chalfant foreshocks. We also thank Rachel Abercrombie for information on recorded foreshock sequences in Califomia and their statistics and Dave Oppenheimer for comments on the Stone Canyon relocations. This paper was greatly improved by careful reviews by Peter Shearer, John Vidale, and Lucy Jones. This work was funded by USGS grant 1434-HQ-96-GR-02716.

\section{References}

Abercrombie, R., and J. Mori, Local observations of the onset of a large earthquake: 28 June 1992 Landers, California, Bull. Seismol. Soc. Am., 84, 725-734, 1994.

Abercrombie, R., D.C. Agnew, and F.K. Wyatt, Testing a model of earthquake nucleation, Bull. Seismol. Soc. Am. , 85, 1873-1878, 1995.
Abercrombie, R., and J. Mori, Foreshock occurrence as a function of mainshock depth and mechanism, Seismo. Res. Lett., 66, 23, 1995.

Bodri, B., and S. Iizuka, On the correlation between earth tides and microseismic activity, Phys. Earth Planet. Inter., 55, 126-134, 1989

Cohee, B. P. and G. C. Beroza, Slip distribution of the 1992 Landers earthquake and its implications for earthquake source mechanics, Bull. Seismol. Soc. Am., 84, 692-712, 1994.

Das, S., and C. Scholz, Theory of time-dependent rupture in the Earth, $J$. Geophys. Res., 86, 6039-6051, 1981.

Deichmann, N., and M. Garcia-Fernandez, Rupture geometry from highprecision relative hypocentre locations of microearthquake clusters, Geophys. J. Int., 110, 501-517, 1992.

Dieterich, J.H., A model for the nucleation of earthquake slip, in Earthquake Source Mechanics, Geophys. Monogr. Ser., vol. 37, edited by S. Das, J. Boatwright, and C.H. Scholz, pp. 37-47, AGU, Washington, D.C., 1986.

Dieterich, J.H., Earthquake nucleation on faults with rate- and statedependent strength, Tectonophysics, 211, 115-134, 1992.

Dodge, D. A., G.C. Beroza, W.L. Ellsworth, and A.T. Cole, Array analysis of micro-earthquakes to determine the cause of velocity changes associated with the 1989 Loma Prieta earthquake, Seismol. Res. Lett., 64, 33, 1993.

Dodge, D. A., G.C. Beroza, and W.L. Ellsworth, Evolution of the 1992 Landers, Califomia, foreshock sequence and its implications for earthquake nucleation, J. Geophys. Res., IO0, 9865-9880, 1995.

Ellsworth, W.L., Three-dimensional structure of the crust and mantle beneath the island of Hawaii, Ph.D. thesis, 327 pp., Mass. Inst. of Technol., Cambridge, 1977.

Ellsworth, W. L., and G.C. Beroza, Seismic evidence for a seismic nucleation phase, Science, 268, 851-855, 1995.

Fremont, M., and S.D. Malone, High precision relative locations of earthquakes at Mount St. Helens, Washington, J. Geophys. Res. 92, 10,223-10,236, 1987.

Harris, R. A., and R. W. Simpson, Changes in static stress on southern California faults after the 1992 Landers earthquake, Nature, 360, 251254, 1992

Hauksson, E., and L. M. Jones, The 1988 and 1990 Upland earthquakes: Left-lateral faulting adjacent to the central transverse ranges, $J$. Geophys. Res., 96, 8143-8165, 1991.

Hauksson, E., L. M. Jones, K. Hutton, and D. Eberhart-Phillips, The 1992 Landers earthquake sequence: Seismological observations, J. Geophys. Res., 98, 19,835-19,858, 1993.

Ishida, M., and H. Kanamori, The foreshock activity of the 1971 San Fernando earthquake, California, Bull. Seismol. Soc. Am., 68, 1265 $1279,1978$.

Johnston, M.J.S., A.T. Linde, and M.T. Gladwin, Near-field high resolution strain measurements prior to the October 18, 1989, Loma Prieta Ms 7.1 earthquake, Geophys. Res. Lett., 17, 1777-1780, 1990.

Johnston, M.J.S., A.T. Linde, and D.C. Agnew, Continuous borehole strain in the San Andreas fault zone before, during and after the 28 June 1992, $M w 7.3$ Landers, California, earthquake, Bull. Seismol. Soc. Am., 84, 799-805, 1994.

Jones, L. M., Foreshocks (1966-1980) in the San Andreas Systern, California. Bull. Seismol. Soc. Am., 74, 1361-1380, 1984.

Jones, L. M., and P. Molnar, Some characteristics of foreshocks and their possible relationship to earthquake prediction and premonitory slip on faults, J. Geophys. Res., 84, 3596-3608, 1979.

Jones, L. M., B. Wang, S. Xu, and T. J. Fitch, The foreshock sequence of the February 4, 1975, Haicheng earthquake ( $M=7.3$ ), J. Geophys. Res., 87, 4575-4584, 1982.

Kanamori, H., and D.L. Anderson, Theoretical basis of some empirical relations in seismology, Bull. Seismol. Soc. Am., 65, 1073-1095, 1975.

Keilis-Borok, V. I., On the estimation of the displacement in an earthquake source and of source dimensions, Ann. Geofis., 12, 205214, 1959.

King, G. C. P., R. S. Stein, and J. Lin, Static stress changes and the triggering of earthquakes, Bull. Seismol. Soc. Am., 84, 935-954, 1994.

Lindh, A., G. Fuis, and C. Mantis, Seismic amplitude measurements suggest foreshocks have different focal mechanisms than aftershocks, Science, 201, 56-59, 1978.

Meredith, P.G., and B.K. Atkinson, Stress corrosion and acoustic emission during tensile crack propagation in Whin Sill dolerite and other basic rocks, Geophys. J. R. Astron. Soc., 75, 1-21, 1983.

Mogi, K., Some discussions on aftershocks, foreshocks and earthquake swarms - The fracture of a semi-infinite body caused by inner stress origin and its relation to earthquake phenomena, 3, Bull. Earthquake Res. Inst. Univ. Tokyo, 41, 615-658, 1963 
Ohnaka, M., Earthquake source nucleation: A physical model for short term precursors. Tectonophysics, 211, 149-178, 1992.

Ohnaka, M., Critical size of the nucleation zone of earthquake rupture inferred from immediate foreshock activity, J. Phys. Earth, 41, 45-46, 1993.

Okada, Y., Internal deformation due to shear and tensile faults in a halfspace, Bull. Seismol. Soc. Am., 82, 1018-1040, 1992.

Poupinet, G., W. L. Ellsworth, and J. Fréchet, Monitoring velocity variations in the crust using earthquake doublets: An application to the Calaveras fault, California, J. Geophys. Res., 89, 5719-5731, 1984.

Press, W.H., B.P. Flannery, S.A. Teukolsky, and W.T. Vettering, Numerical Recipes: The Art of Scientific Computing, Cambridge Univ. Press, New York, 1986.

Reasenberg, P., and D. Oppenheimer, FPFT, FPPLOT and FPPAGE: Fortran computer programs for calculating and displaying earthquake fault-plane solutions, $U$. S. Geol. Surv. Open File Rep., 85-739, 109 Pp., 1985.

Rice, J.R., and M.P. Cleary, Some basic stress diffusion solutions for fluid-saturated elastic porous media with compressible constituents, Rev. Geophys. , 14, 227-241, 1976.

Roecker, S.W., Seismicity and tectonics of the Pamir-Hindu Kush region of central Asia, Ph.D. thesis, 294 pp., Mass. Inst. of Technol., Cambridge, 1981.

Scholz, C.H., The Mechanics of Earthquakes and Faulting, Cambridge Univ. Press, New York., 1990.

Simpson, R. W., and P. A. Reasenberg, Earthquake-induced ${ }_{\text {static stress }}$ changes on central Califomia faults, in The Loma Prieta, California, earthquake of October 17, 1989--Tectonic processes and models, edited by R. W. Simpson, U.S. Geol. Surv. Prof. Pap., 1550-F, 1-131, 1994.
Smith, K.D., and K.F. Priestley, The foreshock sequence of the 1986 Chalfant, California, earthquake, Bull. Seismol. Soc. Am. , 78, 172-187, 1988.

Stein, R. S., G. C. P. King, and J. Lin, Change in failure stress on the southern San Andreas fault system caused by the 1992 magnitude = 7.4 Landers earthquake, Science, 258, 1328-1332, 1992.

VanDecar, J. C., and R. S. Crosson, Determination of teleseismic relative phase arrival times using multi-channel cross-correlation and least squares, Bull. Seismol. Soc. Am., 80, 150-169, 1990.

Wyss, M., and R. E. Habermann, Precursory quiescence before the August 1982 Stone Canyon, San Andreas fault, earthquakes, Pure Appl. Geophys., 126, 333-356, 1988.

Yarnashita, T., and M. Ohnaka, Nucleation process of unstable rupture in the brittle regime: $A$ theoretical approach based on experimentally inferred relations, J. Geophys. Res., 96, 8351-8367, 1991.

Zhou, Y., K.C. McNally, and T. Lay, Analysis of the 1986 Mount Lewis, California, earthquake: Preshock sequence-mainshock-aftershock sequence, Phys. Earth Planet. Inter., 75, 267-288, 1993.

G. C. Beroza and D. A. Dodge, Department of Geophysics, Stanford University, Stanford, CA 94305. (e-mail: beroza@pangea.stanford.edu; dodge@pangea.stanford.edu)

W. L. Ellsworth, U.S. Geological Survey, M.S. 977, Menlo Park, CA 94025. (e-mail: ellswrth@andreas.wr.usgs.gov)

(Received March 8, 1996; revised May 24, 1996; accepted July 18, 1996.) 